\title{
RECOMMENDING INVESTMENT OPPORTUNITIES GIVEN CONGESTION BY ADAPTIVE NETWORK DATA ENVELOPMENT ANALYSIS MODEL: ASSESSING SUSTAINABILITY OF SUPPLY CHAINS
}

\author{
Hossein Hajaji ${ }^{1}$, Sara Yousefi ${ }^{2}$, Reza Farzipoor Saen ${ }^{3, *}$ And Amir Hassanzadeh ${ }^{2}$
}

\begin{abstract}
Nowadays, forward-thinking companies move beyond conventional structures of organizations and consider all parties of the supply chain. The objective of this paper is to present an adaptive network data envelopment analysis (DEA) model to evaluate overall and divisional efficiency of sustainable supply chains in the presence of desirable and undesirable outputs. Our adaptive network DEA model can assess overall and divisional efficiency of supply chains given managerial and natural disposability. Also, it suggests new investment opportunity given congestion type. A case study is presented.
\end{abstract}

Mathematics Subject Classification. 90C08.

Received November 7, 2018. Accepted May 27, 2019.

\section{INTRODUCTION}

Nowadays, due to increasing competition among companies, the importance of supply chain management (SCM) has raised [35]. Therefore, specialists and researchers have focused on SCM [3]. As discussed by Tavassoli et al. [69], SCM was defined in 1980 to consolidate main business processes from the end user to main suppliers. A network of connected organizational units via the flow of materials, information, and money is called a supply chain. The success of corporations depends on their capability to manage the flow of the supply chain [67]. To achieve long term goals of SCM, sustainability principles play an essential role [57]. Sustainable supply chain management (SSCM) is a combination of sustainable development and supply chain management [7]. Sustainable development is defined as "to meet the needs of the present without compromising the ability of future generations to meet their own needs" $[29,31]$. SSCM is a combination of social and environmental factors into economic factors [23]. Previous researches show that the success of SCM depends on strong consideration of sustainability principles $(e . g .,[32,46])$. On the other hand, governments force corporations to pursue

Keywords. Network data envelopment analysis (NDEA), congestion, Sustainable supply chain management (SSCM),

Range-adjusted measure (RAM), sustainable investment, undesirable outputs.

1 Department of Operations Research, Faculty of Management and Accounting, Central Tehran Branch, Islamic Azad University, Tehran, Iran.

2 Young Researchers and Elite Club, Karaj Branch, Islamic Azad University, Karaj, Iran.

3 Faculty of Business, Sohar University, Sohar, Oman.

*Corresponding author: farzipour@yahoo.com 
sustainability factors more seriously [52]. Given these situations, assessing the sustainability of supply chains is critical [33].

Data envelopment analysis (DEA) is one of the methods for evaluating the relative efficiency of decision making units (DMUs) [12,26]. Banker et al. [5] developed a DEA model for measuring relative efficiency in variable return to scale (VRS) context. However, in traditional DEA models, the basic concept is to consider DMUs as black box [15]. In recent years, internal structures of DMUs have been considered, and DEA models have been extended. Such models are named as network DEA models [16]. A couple of scholars have used network DEA to evaluate SSCM practices (e.g., [65]).

In assessing the sustainability of supply chains, there might be undesirable (bad) outputs such as $\mathrm{CO}_{2}$ emission, noise, air pollutions, and dangerous garbage [25,72]. When the production process generates an undesirable output, recognizing undesirable congestion is crucial. In contrast, desirable congestion should also be considered for sustainable economic growth [63]. Congestion is defined as a reduction in one or more inputs which increases one or more outputs. In other words, congestion happens whenever an increase in one or more inputs leads to a decrease in one or more outputs [19]. In this paper, we propose an adaptive network DEA model entitled range adjusted measure (RAM) to evaluate the sustainability of supply chains. An appropriate performance assessment system can assess the efficiency of supply chains for further betterment and making trade-offs between profit and investment [58]. Practitioners try to find a proper method to evaluate the efficiency of supply chains [70]. Efficient supply chains play vital role for companies as a competitive advantage over their rivals. Therefore, sustainability measurement of supply chains is essential [51]. Sustainability of supply chains is a topic that has attracted scholars and managers [68]. Using a pragmatic model to assess sustainable supply chains is a challenging issue for decision makers [28]. In the past decades, sustainable development and sustainability assessment have been the main issues for managers and academia [71]. Despite growing interest in developing tools for sustainability assessment [66], there is scarce of studies on sustainability assessment methods [36]. In this paper, we propose an adaptive network RAM DEA model to measure overall and divisional efficiencies given natural and managerial disposability in the presence of undesirable outputs.

To the best of our knowledge, there is no research to address congestion in supply chains by DEA. The objectives of this paper are as follows: First, an adaptive network RAM model is proposed; Second, overall and divisional efficiencies of supply chains given managerial and natural disposability are assessed; Finally, new investment opportunities given congestion are recommended. Given that natural and managerial disposability are essential topics for the whole supply chain, our proposed model can take into account natural disposability to decrease inputs in order to decrease undesirable outputs. Simultaneously, by promoting an appropriate and targeted investment with managerial disposability perspective, without a reduction in inputs, we can decrease undesirable outputs and increase desirable outputs.

In summary, contributions of this paper are as follows:

- For the first time, an adaptive network RAM model is proposed to measure overall and divisional efficiencies in the presence of both desirable and undesirable outputs.

- For the first time, an adaptive network RAM model is used to recommend new investment opportunities given congestion.

- A case study is given.

Subsequent sections of this paper are as follows: Section 2 illustrates literature review. Section 3 outlines proposed model. Section 4 demonstrates a case study. Managerial implications are given in Section 5. Conclusions are presented in Section 6.

\section{LiterATURE REVIEW}

\subsection{Network DEA}

For the first time, Charnes et al. [11] introduced the two-phase DEA model. Seiford and Zhu [54] presented a CCR (Charnes-Cooper-Rhodes) output-oriented two-stage DEA model to measure the efficiency of US 
commercial banks. In their proposed method, areas for improving banking efficiencies are determined. Färe and Grosskopf [24] developed a network DEA model to assess the efficiency of the Swedish Institute for Health Economics. Kao and Hwang [38] demonstrated a two-stage CCR model to calculate efficiencies of the whole process with two related sub-processes for non-life insurance companies in Taiwan. Chen et al. [14] improved the work of Kao and Hwang [38] and proposed an additive method to measure the efficiency of two-stage processes and the efficiency decomposition for both constant returns to scale (CRS) and variable returns to scale (VRS). Chen [13] proposed a network DEA model to deal with dynamic effect within a network. Chen et al. [17] demonstrated a double stage DEA model to evaluate SSCM design efficiency. Agrell and Hatami-Marbini [1] proposed a two-stage DEA model to solve four identified related problems regarding DEA and supply chain performance measurement. Chen et al. [15] demonstrated a two-stage DEA model based on VRS to measure divisional and overall efficiencies, simultaneously. Mirhedayatian et al. [42] extended a new multiple stage DEA model to evaluate green SCM in the presence of dual-role factors, undesirable outputs, and fuzzy data. Badiezadeh et al. [4] developed a network DEA model for calculating pessimistic and optimistic efficiency in SSCM. Koronakos et al. [40] reformulated some of the main network DEA methods in a common modelling framework. They illustrated that the leader-follower method, multiplicative and additive decomposition methods, min-max method, and "weak-link" approach could be modeled in a multi-objective programming framework. Despotis et al. [22] presented a network DEA method to estimate unique efficiency scores for each stage and overall network. For a short overview of network DEA, see Kao [37].

\subsection{RAM Network DEA}

Maruyama [43] developed a RAM network model to evaluate overall and divisional efficiencies. However, he did not differentiate the types of links and outputs in networks. Avkiran and McCrystal [2] compared the RAM network model with network slacks-based measure (SBM) model. Izadikhah and Farzipoor Saen [33] developed a two-stage RAM model to assess the sustainability of the supply chain in the presence of negative data. In their proposed model, each DMU is divided into two sub-DMUs assuming that all intermediate products are inputs of sub-DMUs in the second stage.

\subsection{Desirable and undesirable outputs in DEA}

Primary DEA models such as CCR, BCC (Banker-Charners-Cooper), SBM, additive, and RAM models deal with inputs and desirable (good) outputs [42]. Scheel [53] investigated different methods for dealing with outputs in DEA and proposed new radial measure. Seiford and Zhu [55] proposed a DEA model to deal with undesirable outputs based on BCC model. They used classification invariance property to improve performance with increasing the desirable outputs and decreasing the undesirable outputs. Färe and Grosskopf [25] modified a model which has been introduced by Seiford and Zhu [55] by reversing' the bad outputs. Farzipoor Saen [27] extended a new DEA model for supplier selection in the presence of imprecise data and undesirable outputs. Sueyoshi and Goto [60] assessed operational, environmental, and unified efficiency scores of US coal-fired power plants in the presence of undesirable outputs. Sueyoshi and Goto [61] proposed a DEA model for environmental evaluation in the presence of undesirable outputs. Sueyoshi and Goto [62] developed a non-radial DEA model to measure unified efficiency, unified efficiency under natural disposability, and unified efficiency under managerial disposability for environmental evaluation in the presence of undesirable outputs. A neutral SBM model given undesirable outputs was developed by Zoroufchi et al. [72] to select the best suppliers. Izadikhah and Farzipoor Saen [34] developed a stochastic two-stage DEA model to deal with undesirable outputs. In their proposed model, the first stage creates additional final output and the second stage utilizes additional input, and parts of intermediate products are considered as the final output. Their model was applied to assess the sustainability of pasta supply chains.

However, none of the above-mentioned references have dealt with network RAM model in the presence of desirable and undesirable outputs given managerial and natural disposability. Furthermore, none of the abovementioned references have assessed congestion in DMUs with network structures. 
TABLE 1. Notations.

\begin{tabular}{ll}
\hline \hline Notations & Descriptions \\
\hline DMU $_{o}$ & DMU under evaluation \\
$X_{i j}$ & ith input of DMU $\mathrm{DM}_{j}$ \\
$Y_{r j}$ & $r$ th input of DMU \\
$X_{i o}$ & ith input of DMU \\
$Y_{r o}$ & $r$ th input of DMU \\
$\lambda_{j}$ & jth intensity variable \\
$u_{r}$ & Output weight \\
$v_{i}$ & Input weight \\
$v_{o}$ & Weight of input for DMU \\
$R_{r}^{+}$ & Data range related to $r$ th Output \\
$R_{i}^{-}$ & Data range related to ith input \\
$m$ & Number of inputs \\
$s$ & Number of outputs \\
$R_{i}^{x}$ & Range related to $i$ th input \\
$d_{i}^{x+}$ & Slack of $i$ th desirable input \\
$d_{i}^{x-}$ & Slack of $i$ th undesirable input \\
$R_{r}^{g}$ & Data range related to $r$ th desirable output \\
$d_{r}^{g}$ & Slack of $r$ th desirable output \\
$R_{f}^{b}$ & Data range related to $f$ th undesirable output \\
$d_{f}^{b}$ & Slack of $f$ th undesirable output \\
$x_{i o}$ & ith input of DMU \\
$g_{r o}$ & $r$ th desirable output of DMU \\
$b_{f o}$ & fth undesirable output of DMU \\
$d_{i}^{x}$ & Slack of $i$ th input \\
$R_{q}^{x}$ & Range related to $q$ th input \\
$d_{q}^{x}$ & Slack of $q$ th input \\
$d_{i}^{x}$ & Slack of $i$ th input \\
$R_{q}^{x}$ & Range related to $q$ th input \\
$x_{i o}^{-}$ & ith input of DMU \\
$d_{q}^{x}$ & Slack of $q$ th input \\
$x_{q o}^{+}$ & Slack of $q$ th input of DMU \\
$z_{q}$ & Dual variable \\
$w_{f}$ & Dual variable \\
$\sigma$ & Dual variable \\
$W_{h}$ & Weight of division $h$ \\
$R_{i}^{h x}$ & Range related to $i$ th input of division $h$ \\
$d_{i}^{h x}$ & Slack of $i$ th input of division $h$ \\
$R_{q}^{h x}$ & Range related to $q$ th input of division $h$ \\
$d_{q}^{h x}$ & Slack of $q$ th input for division $h$ \\
\hline &
\end{tabular}

\section{Proposed adaptive network RAM-Unified EFFiciency NATURAL AND MANAGERIAL (NRAM-UENM) MODEL}

\subsection{Review of RAM DEA model}

One of the DEA models is RAM model. RAM model was developed by Cooper et al. [20]. Table 1 illustrates used notations in this paper. 
TABle 1. Continued.

\begin{tabular}{ll}
\hline \hline Notations & Descriptions \\
\hline$R_{r}^{h g}$ & Range related to $r$ th desirable output for division $h$ \\
$d_{r}^{h g}$ & Slack of $r$ th desirable output for division $h$ \\
$R_{f}^{h b}$ & Range related to $f$ th undesirable output for division $h$ \\
$d_{f}^{h b}$ & Slack of $f$ th undesirable output for division $h$ \\
$\lambda_{j}^{h}$ & Intensity vector corresponding to division $h$ \\
$x_{i o}^{h}$ & Input of DMU in division $h$ \\
$X_{q j}^{h}$ & Input of $\mathrm{DMU}_{j}$ in division $h$ \\
$x_{q o}^{h}$ & qth input of DMU $\mathrm{DM}_{o}$ in division $h$ \\
$d_{r}^{h g}$ & Slack of $r$ th desirable output in division $h$ \\
$g_{r o}^{h}$ & $r$ th desirable output of DMU $\mathrm{D}_{o}$ in division $h$ \\
$d_{f}^{h b}$ & Slack of $f$ th undesirable output in division $h$ \\
$b_{f o}^{h}$ & $f$ th undesirable output of DMU $\mathrm{DU}_{o}$ in division $h$ \\
$Z_{(k h) \text { in }} h$ & Intermediate measures from division $k$ to division $h$ \\
$S_{o(k h) \text { in }}$ & Slack of DMU $\mathrm{D}_{o}$ in division $h$ \\
$Z_{o(k h) \text { in }}$ & \\
$Z_{(k h) \text { out }}$ & \\
$S_{o(k h) \text { out }}$ & \\
$Z_{o(k h) \text { out }}$ & Intermediate measures from \\
$Z_{(k h) \text { free }}$ & division $k$ to division $h$ \\
$S_{o(k h) \text { free }}$ & \\
$Z_{o(k h) \text { free }}$ & \\
$Z_{(k h) \text { fix }}$ & \\
$Z_{o(k h) \text { fix }}$ & \\
\hline
\end{tabular}

RAM model developed by Cooper et al. [20] is as follows:

$$
\begin{aligned}
& \text { Maximize } \sum_{r=1}^{s} u_{r} y_{r o}+v_{o} \\
& \text { subject to } \\
& \sum_{r=1}^{s} u_{r} y_{r j}-\sum_{i=1}^{m} v_{i} x_{i j}+v_{o} \leq 0 ; \quad j=1, \ldots, n \\
& \sum_{i=1}^{m} v_{i} x_{i o}=1 \\
& -u_{r} \leq-1 / R_{r}^{+}(m+s) \\
& -v_{i} \leq-1 / R_{i}^{-}(m+s) \\
& v_{o} \text { free in sign. }
\end{aligned}
$$

Thereafter, model (3.1) was extended by Sueyoshi and Goto [62] to measure unified efficiency (UE), unified efficiency under natural (UEN) disposability, and unified efficiency under managerial (UEM) disposability. As discussed by Sueyoshi and Goto [62], UE deals with increase and decrease of inputs to decrease undesirable output directional vector. To calculate UE, Sueyoshi and Goto [62] proposed following model:

$$
\begin{array}{ll}
\text { Maximize } & \sum_{i=1}^{m} R_{i}^{x}\left(d_{i}^{x+}+d_{i}^{x-}\right)+\sum_{r=1}^{s} R_{r}^{g} d_{r}^{g}+\sum_{f=1}^{h} R_{f}^{b} d_{f}^{b} \\
\text { subject to } & (i=1, \ldots, m) \\
\sum_{j=1}^{n} X_{i j} \lambda_{j}-d_{i}^{x+}+d_{i}^{x-}=x_{i o} & (r=1, \ldots, s) \\
\sum_{j=1}^{n} g_{r j} \lambda_{j}-d_{r}^{g}=g_{r o} &
\end{array}
$$




$$
\begin{aligned}
& \sum_{j=1}^{n} b_{f j} \lambda_{j}+d_{f}^{b}=b_{f o} \quad(f=1, \ldots, h) \\
& \sum_{j=1}^{n} \lambda_{j}=1 \lambda_{j} \geq 0 \quad(j=1, \ldots, n) \\
& d_{i}^{x+} \geq 0(i=1, \ldots, m) \quad d_{i}^{x-} \geq 0 \quad(i=1, \ldots, m) \\
& d_{r}^{g} \geq 0(r=1, \ldots, s) \quad d_{f}^{b} \geq 0 \quad(f=1, \ldots, h) .
\end{aligned}
$$

After running model (3.2), UE measure is as follows:

$$
\text { UE measure }=1-\left(\sum_{i=1}^{m} R_{i}^{x}\left(d_{i}^{x+}+d_{i}^{x-}\right)+\sum_{r=1}^{s} R_{r}^{g} d_{r}^{g}+\sum_{f=1}^{h} R_{f}^{b} d_{f}^{b}\right) .
$$

UEN disposability considers a decrease in input vector to decrease undesirable output directional vector. The model proposed by Sueyoshi and Goto [62] for calculating UEN is as follows:

$$
\begin{array}{ll}
\text { Maximize } \quad \sum_{i=1}^{m} R_{i}^{x} d_{i}^{x}+\sum_{r=1}^{s} R_{r}^{g} d_{r}^{g}+\sum_{f=1}^{h} R_{f}^{b} d_{f}^{b} \\
\text { subject to } & (i=1, \ldots, m) \\
\sum_{j=1}^{n} X_{i j} \lambda_{j}+d_{i}^{x}=x_{i o} & (r=1, \ldots, s) \\
\sum_{j=1}^{n} g_{r j} \lambda_{j}-d_{r}^{g}=g_{r o} & (f=1, \ldots, h) \\
\sum_{j=1}^{n} b_{f j} \lambda_{j}+d_{f}^{b}=b_{f o} & (j=1, \ldots, n) \\
\sum_{j=1}^{n} \lambda_{j}=1 \quad \lambda_{j} \geq 0 & \\
d_{i}^{x} \geq 0 \quad(i=1, \ldots, m) & (f=1, \ldots, h) .
\end{array}
$$

After running model (3.4), UEN disposability is as follows:

$$
\mathrm{UEN}=1-\left(\sum_{i=1}^{m} R_{i}^{x} d_{i}^{x}+\sum_{r=1}^{s} R_{r}^{g} d_{r}^{g}+\sum_{f=1}^{h} R_{f}^{b} d_{f}^{b}\right) .
$$

UEM disposability considers an increase in input vector to decrease undesirable output directional vector. Sueyoshi and Goto [62] proposed following model to calculate UEM:

$$
\begin{array}{ll}
\text { Maximize } \quad \sum_{i=1}^{m} R_{i}^{x} d_{i}^{x}+\sum_{r=1}^{s} R_{r}^{g} d_{r}^{g}+\sum_{f=1}^{h} R_{f}^{b} d_{f}^{b} \\
\text { subject to } & (i=1, \ldots, m) \\
\sum_{j=1}^{n} X_{i j} \lambda_{j}-d_{i}^{x}=x_{i o} & (r=1, \ldots, s) \\
\sum_{j=1}^{n} g_{r j} \lambda_{j}-d_{r}^{g}=g_{r o} & (f=1, \ldots, h) \\
\sum_{j=1}^{n} b_{f j} \lambda_{j}+d_{f}^{b}=b_{f o} & (j=1, \ldots, n) \\
\sum_{j=1}^{n} \lambda_{j}=1 \quad \lambda_{j} \geq 0 & \\
d_{i}^{x} \geq 0 \quad(i=1, \ldots, m) & (f=1, \ldots, h)
\end{array}
$$


After running model (3.6), UEM disposability is calculated as follows:

$$
\mathrm{UEM}=1-\left(\sum_{i=1}^{m} R_{i}^{x} d_{i}^{x}+\sum_{r=1}^{s} R_{r}^{g} d_{r}^{g}+\sum_{f=1}^{h} R_{f}^{b} d_{f}^{b}\right) .
$$

Later on, Sueyoshi and Wang [64] developed an integrated RAM model to calculate UENM disposability in presence of desirable congestion. Model of UENM measure is as follows:

$$
\begin{array}{ll}
\text { Maximize } \quad \sum_{i=1}^{m^{-}} R_{i}^{x} d_{i}^{x}+\sum_{r=1}^{s} R_{q}^{x} d_{q}^{x}+\sum_{f=1}^{h} R_{f}^{b} d_{f}^{b} \\
\text { subject to } & \left(i=1, \ldots, m^{-}\right) \\
\sum_{j=1}^{n} x_{i j}^{-} \lambda_{j}+d_{i}^{\chi}=x_{i o}^{-} & \left(q=1, \ldots, m^{+}\right) \\
\sum_{j=1}^{n} x_{q j}^{+} \lambda_{j}-d_{q}^{\chi}=x_{q o}^{+} & (r=1, \ldots, s) \\
\sum_{j=1}^{n} g_{r j} \lambda_{j}=g_{r o} & (f=1, \ldots, h) \\
\sum_{j=1}^{n} b_{f j} \lambda_{j}-d_{f}^{b}=b_{f o} & \\
\sum_{j=1}^{n} \lambda_{j}=1, & \left(i=1, \ldots, m^{-}\right) \\
\lambda_{j} \geq 0 \quad(j=1, \ldots, n), \quad d_{i}^{\chi} \geq 0 & \\
d_{q}^{\chi} \geq 0 \quad\left(q=1, \ldots, m^{+}\right), \quad d_{f}^{b} \geq 0 & (f=1, \ldots, h) .
\end{array}
$$

After running model (3.8), UENM disposability is calculated as follows:

$$
\mathrm{UENM}=1-\left(\sum_{i=1}^{m^{-}} R_{i}^{x} d_{i}^{x}+\sum_{r=1}^{s} R_{q}^{x} d_{q}^{x}+\sum_{f=1}^{h} R_{f}^{b} d_{f}^{b}\right) .
$$

Dual of model (3.8) is as follows:

$$
\begin{array}{ll}
\text { Minimize } \sum_{i=1}^{m^{-}} v_{i} x_{i k}^{-}-\sum_{q=1}^{m^{+}} z_{q} x_{q k}^{+}+\sum_{r=1}^{s} u_{r} g_{r k}-\sum_{f=1}^{h} w_{f} b_{f k}+\sigma \\
\text { subject to } \\
\sum_{i=1}^{m^{-}} v_{i} x_{i j}^{-}-\sum_{q=1}^{m^{+}} z_{q} x_{q j}^{+}+\sum_{r=1}^{s} u_{r} g_{r j}-\sum_{f=1}^{h} w_{f} b_{f j}+\sigma \geq 0 & (j=1, \ldots, n) \\
v_{i} \geq R_{i}^{\chi} & \left(i=1, \ldots, m^{-}\right) \\
z_{q} \geq R_{q}^{\chi} & \left(q=1, \ldots, m^{+}\right) \\
u_{r} \text { free in sign } & (r=1, \ldots, s) \\
w_{f} \geq R_{f}^{b} & (f=1, \ldots, h) . \\
\sigma \text { free in sign } &
\end{array}
$$

$R_{i}^{x}$ is equal with inputs range which is obtained by following expression:

$$
R_{i}^{x}=1 /\left(\max \left\{x_{i j} \mid j=1, \ldots, n\right\}-\min \left\{x_{i j} \mid j=1, \ldots, n\right\}\right)(m+s+h) .
$$

$R_{r}^{g}$ is equal with desirable outputs range which is used in following expression:

$$
R_{r}^{g}=1 /\left(\max \left\{g_{r j} \mid j=1, \ldots, n\right\}-\min \left\{g_{r j} \mid j=1, \ldots, n\right\}\right)(m+s+h) .
$$

$R_{f}^{b}$ is range of undesirable output which is calculated by following expression:

$$
R_{f}^{b}=1 /\left(\max \left\{b_{f j} \mid j=1, \ldots, n\right\}-\min \left\{b_{f j} \mid j=1, \ldots, n\right\}\right)(m+s+h) .
$$




\subsection{Adaptive RAM network model with desirable and undesirable outputs}

Here, we propose a RAM network model in the presence of desirable and undesirable outputs. Now, we extend model (3.8).

\subsubsection{Objective function}

Due to network structure of our model, objective function has been modified as below:

$$
\text { Maximize } \quad \sum_{h=1}^{k} W_{h}\left(\sum_{i=1}^{h} R_{i}^{h x} d_{i}^{h x}+\sum_{i=1}^{h} R_{r}^{h g} d_{r}^{h g}+\sum_{i=1}^{h} R_{f}^{h b} d_{f}^{h b}\right) .
$$

$W_{h}$ is weight of each division. Furthermore, range of inputs, desirable outputs, and undesirable outputs are given as below:

$$
\begin{aligned}
& R_{i}^{h x}=1 /\left(\max \left\{x_{i j}^{h} \mid j=1, \ldots, n\right\}-\min \left\{x_{i j}^{h} \mid j=1, \ldots, n\right\}\right)(m+s+h) \\
& R_{i}^{h g}=1 /\left(\max \left\{g_{r j}^{h} \mid j=1, \ldots, n\right\}-\min \left\{g_{r j}^{h} \mid j=1, \ldots, n\right\}\right)(m+s+h) \\
& R_{i}^{h b}=1 /\left(\max \left\{b_{f j}^{h} \mid j=1, \ldots, n\right\}-\min \left\{b_{f j}^{h} \mid j=1, \ldots, n\right\}\right)(m+s+h) .
\end{aligned}
$$

\subsubsection{Input, output, and fixed link definition}

$\mathrm{DMU}_{j}$ is $j$ th supply chain (network) which has $K_{n}(K=1,2, \ldots, n)$ divisions. $m_{k}$ is number of inputs. $x_{i j k}$ is $i$ th input of $\mathrm{DMU}_{j}$ in division $K$ which is as follows:

$$
x_{i j k} \in R_{+}\left(i=1, \ldots, m_{k} ; j=1, \ldots, n ; k=1, \ldots, n\right),
$$

where $r_{k}$ is number of outputs. $y_{r j k}$ is $r$ th output of $\mathrm{DMU}_{j}$ in division $K$ which is as follows:

$$
y_{r j k} \in R_{+}\left(r=1, \ldots, r_{k} ; j=1, \ldots, n ; k=1, \ldots, n\right),
$$

where $z_{r j k}$ is as link; i.e., output of $\mathrm{DMU}_{j}$ from $k$ th division to $h$ th division:

$$
z_{r j k} \in R_{+}\left(r=1, \ldots, r_{k} ; j=1, \ldots, n ; k=1, \ldots, n\right) .
$$

\subsection{3. $D M U$ under evaluation}

DMU under evaluation $\left(\mathrm{DMU}_{o}\right)$ and input and output constraints of

$\mathrm{DMU}_{o}$ are as follows:

$$
\begin{array}{ll}
X_{o k}=X_{k} \lambda_{k}+S_{k o}^{-} & (\forall k) \\
Y_{o k}=Y_{k} \lambda_{k}+S_{k o}^{+} & (\forall k) \\
\sum_{j=1}^{n} \lambda_{k}=1 & (\forall j, \forall k) \\
\lambda_{k} \geq 0, S_{k o}^{-} \geq 0, S_{k o}^{+} \geq 0 & (\forall k),
\end{array}
$$

where $X_{k}=\left(x_{1 k}, \ldots, x_{n k}\right) \in R^{m_{k} \times n}$ is an input matrix and $Y_{k}=\left(y_{1 k}, \ldots, y_{n k}\right) \in R^{r_{k} \times n}$ is an output matrix. $S_{k o}^{-}$is input slack variable and $S_{k o}^{+}$is output slack variable. $\left(\lambda_{j k}\right.$ is vector of intensity related to $K$ th division. Also,

$$
\begin{aligned}
& \text { free link } \quad Z_{o(k h) \text { free }}=Z_{(k h) \text { free }} \lambda_{k}+S_{o(k h) \text { free }} ; \quad S_{o(k h) \text { free }} \in R^{L_{k h}} \\
& \text { fixed link } \quad Z_{o(k h) \text { fixed }}=Z_{(k h) \text { fixed }} \lambda_{k} ; \quad(\forall(k, h) \text { fixed }) \\
& \text { bad link (input link) } \quad Z_{o(k h) \text { in }}=Z_{(k h) \text { in }} \lambda_{k}+S_{o(k h) \text { in }} ; \quad S_{o(k h) \text { in }} \in R^{L_{k h(\mathrm{in})}} \\
& \text { good link (output link) } \quad Z_{o(k h) \text { out }}=Z_{(k h) \text { out }} \lambda_{k}+S_{o(k h) \text { out }} ; \quad S_{o(k h) \text { out }} \in R^{L_{k h(\text { out })}} \text {. }
\end{aligned}
$$




\subsubsection{Our proposed NRAM-UENM model}

At this juncture, our new NRAM-UENM model is presented as follows:

$$
\begin{aligned}
& \text { Maximize } \quad \sum_{h=1}^{k} W_{h}\left(\sum_{i=1}^{m h^{-}} R_{i}^{h x} d_{i}^{h x}+\sum_{q=1}^{m h^{+}} R_{q}^{h x} d_{q}^{h x}+\sum_{r=1}^{s} R_{r}^{h g} d_{r}^{h g}+\sum_{f=1}^{l} R_{f}^{h b} d_{f}^{h b}\right) \\
& \text { subject to } \\
& \sum_{i=1}^{n} X_{i j}^{h} \lambda_{j}^{h}+d_{i}^{h x}=x_{i o}^{h} ; \quad\left(i=1, \ldots, m^{-}\right) \\
& \sum_{q=1}^{n} X_{q j}^{h} \lambda_{j}^{h}-d_{i}^{h x}=x_{q o}^{h} ; \quad\left(i=1, \ldots, m^{+}\right) \\
& \sum_{j=1}^{n} g_{r j}^{h} \lambda_{j}^{h}-d_{r}^{h g}=g_{r o}^{h} ; \quad(r=1, \ldots, s) \\
& \sum_{j=1}^{n} b_{f j}^{h} \lambda_{j}^{h}+d_{f}^{h b}=b_{f o}^{h} ; \quad(f=1, \ldots, l) \\
& \sum_{j=1}^{n} Z_{(k h) \text { in }} \lambda_{j}^{h}+S_{o(k h) \text { in }}=Z_{o(k h) \text { in }} ; \quad\left((k h) \text { in }=1, \ldots, \text { link in } \text { in }_{k}\right) \\
& \sum_{j=1}^{n} Z_{(k h) \text { out }} \lambda_{j}^{h}-S_{o(k h) \text { out }}=Z_{o(k h) \text { out }} ; \quad\left((k h) \text { out }=1, \ldots, \text { link out }_{k}\right) \\
& \sum_{j=1}^{n} Z_{(k h) \text { free }} \lambda_{j}^{h}+S_{o(k h) \text { free }}=Z_{o(k h) \text { free }} \\
& \sum_{j=1}^{n} Z_{(k h) \text { fixed }}=Z_{o(k h) \text { fixed }} \text {; } \\
& \sum_{j=1}^{n} \lambda_{j}^{h}=1 \\
& d_{i}^{h x}, d_{r}^{h g}, d_{f}^{h b}, S_{o(k h) \text { in }}, S_{o(k h) \text { out }} \geq 0 ; \\
& S_{o(k h) \text { free, free in sign. }}
\end{aligned}
$$

Model (3.29) is used to calculate overall unified inefficiency. Overall UE under natural and managerial disposability is determined by:

$$
\mathrm{UENM}=1-\sum_{h=1}^{k} W_{h}\left(\sum_{i=1}^{m h^{-}} R_{i}^{h x} d_{i}^{h x}+\sum_{q=1}^{m h^{+}} R_{q}^{h x} d_{q}^{h x}+\sum_{r=1}^{s} R_{r}^{h g} d_{r}^{h g}+\sum_{f=1}^{l} R_{f}^{h b} d_{f}^{h b}\right) .
$$

A divisional UE is measured by:

$$
\mathrm{UENM}=1-\sum_{h=1}^{k} W_{h}\left(\sum_{i=1}^{m h^{-}} R_{i}^{h x} d_{i}^{* h x}+\sum_{q=1}^{m h^{+}} R_{q}^{h x} d_{q}^{* h x}+\sum_{r=1}^{s} R_{r}^{h g} d_{r}^{* h g}+\sum_{f=1}^{l} R_{f}^{h b} d_{f}^{* h b}\right),
$$

where $d_{i}^{* h x}, d_{q}^{* h x}, d_{r}^{* h g}, d_{f}^{* h b}$ are surplus slacks which is obtained by model (3.29).

\subsubsection{Dual NRAM-UENM model}

Dual of model (3.29) is as follows:

$$
\begin{aligned}
& \text { Minimize } \quad \sum_{h=1}^{k} W_{h}\left(\sum_{i=1}^{m h^{-}} V_{i}^{h x} X_{i j}^{h}+\sum_{q=1}^{m h^{+}} Z_{q}^{h x} X_{q j}^{h}+\sum_{r=1}^{s} T_{r}^{h g} g_{r j}^{h}+\sum_{f=1}^{l} N_{f}^{h b} d_{f}^{h b}+\sum_{f=1}^{p} U_{p}^{h b} d_{p}^{h b}+\sigma\right) \\
& \text { subject to } \\
& \sum_{h=1}^{k} W_{h}\left(\sum_{i=1}^{m h^{-}} V_{i}^{h x} X_{i j}^{h}+\sum_{q=1}^{m h^{+}} Z_{q}^{h x} X_{q j}^{h}+\sum_{r=1}^{s} T_{r}^{h g} g_{r j}^{h}+\sum_{f=1}^{l} N_{f}^{h b} d_{f}^{h b}+\sum_{f=1}^{p} U_{p}^{h b} d_{p}^{h b}+\sigma\right) \geq 0 \quad(j=1, \ldots, n) \\
& V_{i}^{h x} \geq R_{i}^{h x} \quad\left(i=1, \ldots, m^{-}\right) \\
& Z_{q}^{h x} \geq R_{q}^{h x} \quad\left(q=1, \ldots, m^{+}\right)
\end{aligned}
$$




$$
\begin{array}{ll}
T_{r}^{h g} \geq R_{r}^{h g} & (r=1, \ldots, s) \\
N_{f}^{h b} \geq R_{f}^{h b} & (f=1, \ldots, l) \\
U_{p}^{h b}: \text { free } & \\
\sigma: \text { free, } &
\end{array}
$$

where $V_{i}^{h x}, Z_{q}^{h x}, T_{r}^{h g}, N_{f}^{h b}, U_{p}^{h b}$, and $\sigma$ are dual variables. Al, $\sigma$ helps to recognize type of congestion in each division of supply chain [64].

\section{Case Study}

Paper recycling has four divisions. The first division includes the companies that convert natural raw materials to paper which are known as paper manufacturing companies. The second division includes consumers that use paper and try to reduce wastes from their pcesses. The third division includes companies that collect waste papers. The fourth division includes paper recycling firms that purchase waste paper from the third division. They process wapers a convert them into other paper products.

Here, we assess the overall unified and unified divisional efficiency (sustainability) of paper recycling supply chain under natural and managerial disposability. Figure 1 depicts the Iranian paper's recycling supply chain which consists of 4 divisions. Divisions include paper mills and import companies, waste paper producer, waste paper collecting companies, and paper recycling firms. In this study, the sustainability of 50 DMUs (supply chains) is assessed. Sustainability criteria are taken from previous researches such as Neto et al. [47], Sueyoshi and Wang [64], Carlsson et al. [14], and Philpott and Everett [49]. Criteria are as follows:

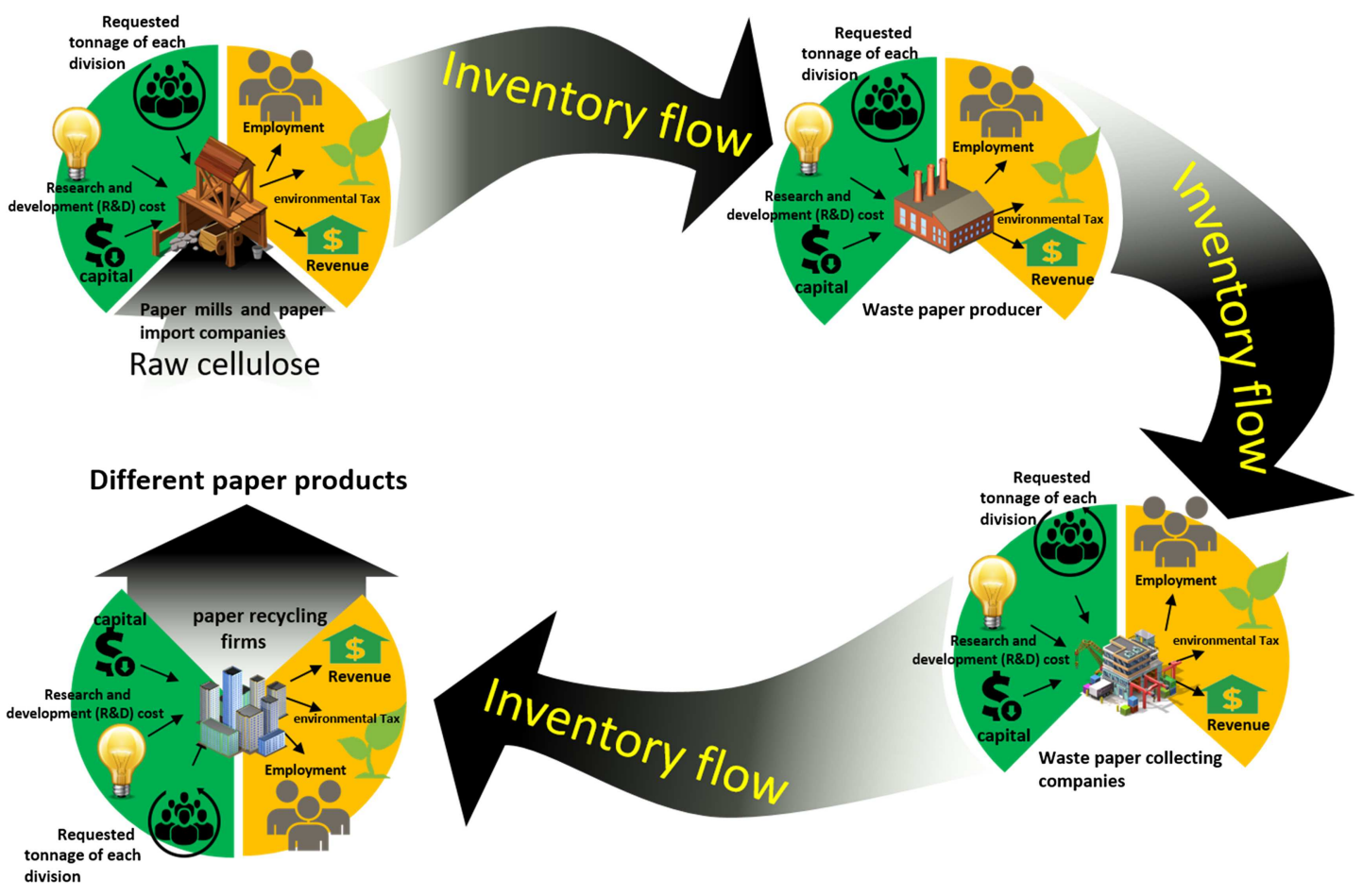

FigURE 1. Structure of the paper's recycling supply chain. 


\section{Inputs:}

Raw cellulose, capital, research and development (R\&D) cost, requested tonnage of each division. Raw cellulose belongs to the first division.

\section{Outputs:}

Number of employment of each division, payments to environmental organization, and revenues are outputs. Payments to the Iranian Department of Environmental are the penalty of emitted pollution which is an undesirable output.

\section{Fixed link:}

Inventory flow is considered as a fixed link.

Datasets of inputs, outputs, and fixed link are reported in Tables A.1-A.4 (see Appendix).

\subsection{Overall unified and divisional UE}

Overall unified inefficiency scores are calculated by model (3.29). Overall UE scores are obtained by Expression (3.30). Divisional UE scores are calculated by model (3.31) and surplus slacks which are calculated by model (3.29). Table 2 shows obtained results for overall unified and divisional UE scores. Table 2 represents the overall efficiency of each supply chain which is introduced as a unique DMU. Also, it depicts the efficiency scores of each division in the supply chain. Efficiency scores are reported based on sustainability factors. Figure 2 shows the overall unified efficiency score of each DMU. It is seen that DMUs 19 and 34 have the highest efficiency scores.

Results of overall UE scores of supply chains are depicted in Figure 2.

Average of overall UE (sustainability) scores is $58.8 \%$. As addressed in Table 2, efficiency scores of DMUs 19 and 34 in each division are unity. Therefore, overall UE scores of DMUs 19 and 34 are unity. Analyzing divisional UE is crucial for decision-makers as supply chain weaknesses can be identified. Average of divisional UE scores of 50 supply chains are shown in Figure 3.
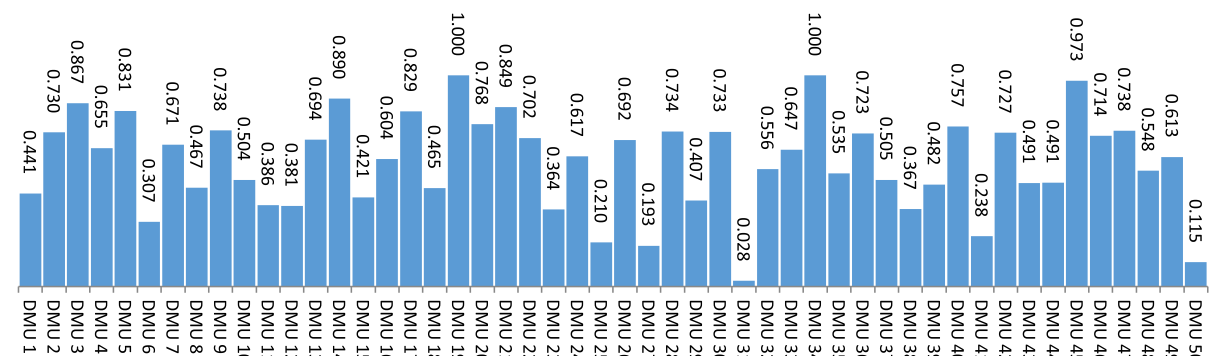

Figure 2. Overall UE scores.

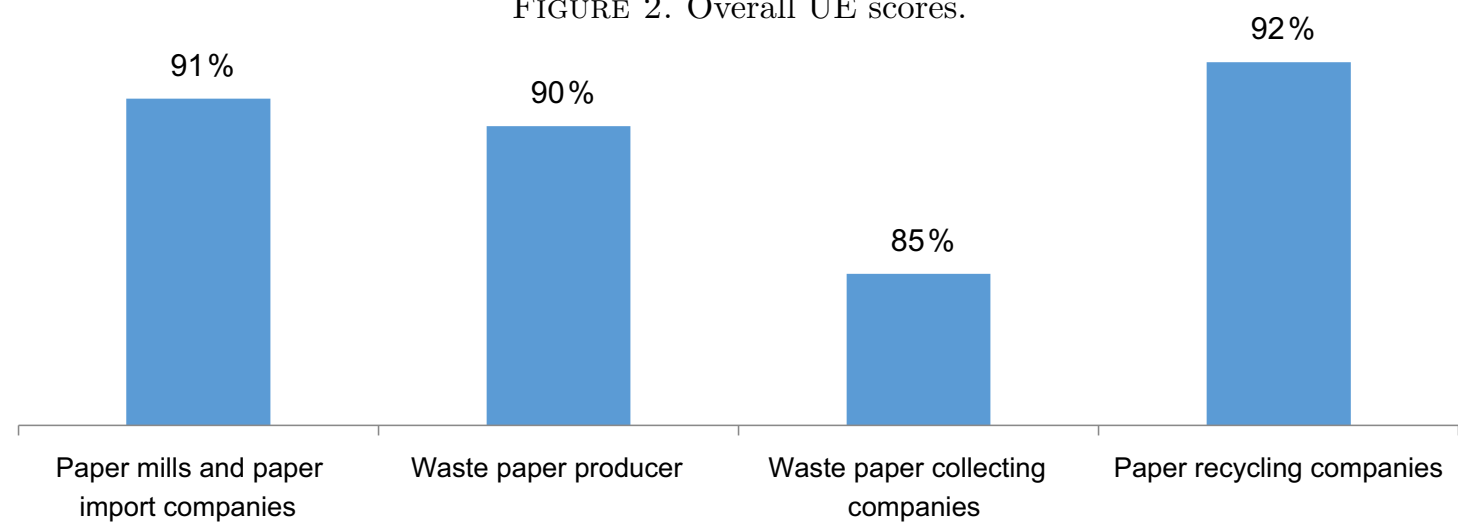

Figure 3. Average of divisional UE scores. 


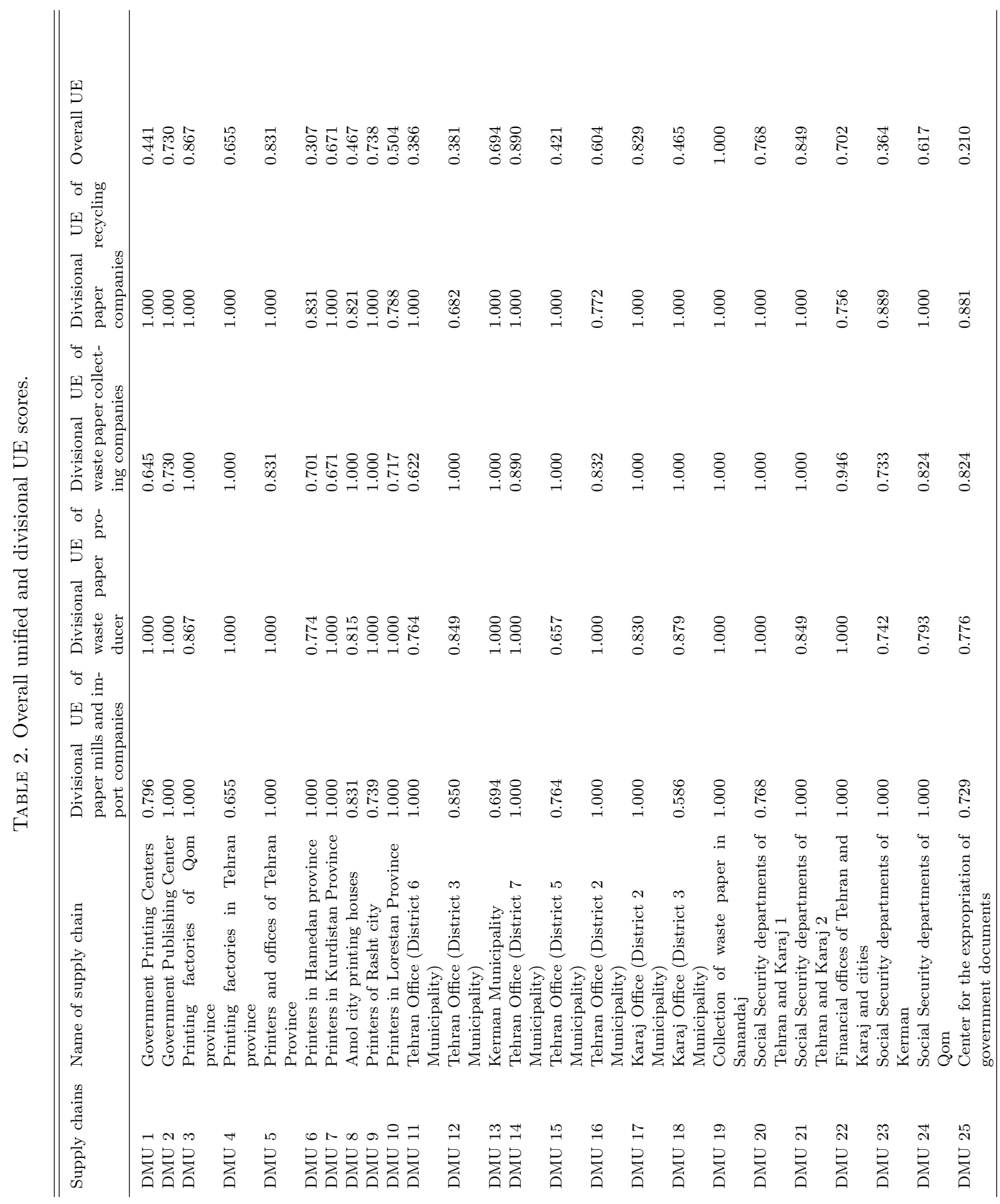




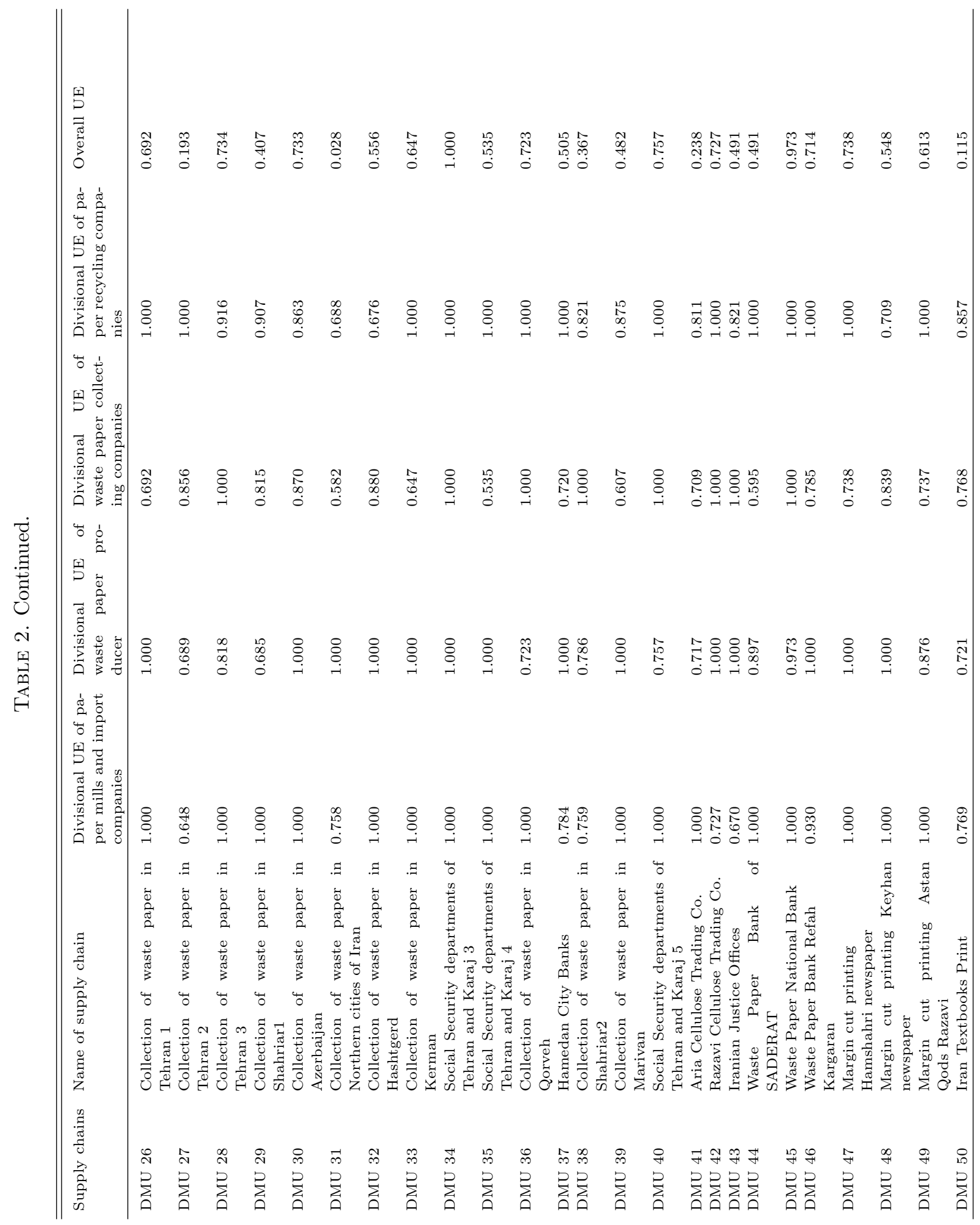


As mentioned in Figure 3, the divisional UE score of waste paper collecting companies is lower than other divisions. Therefore, this division has a weakness in the supply chain.

\subsection{Congestion in a supply chain}

Given returns to scale and existence of equal constraint which causes creating supporting hyperplane in production possibility set (PPS), the border between desirable outputs and inputs can be recognized [64]. $\sigma$ in model $((3.32))$ represents the type of congestion in each division of the supply chain. Recognizing congestion type helps decision makers to decide on areas of sustainable investment [64]. Table 3 depicts the congestion type of divisions of supply chains. Given arrow signs, type of congestion, positive (desirable) and negative (undesirable), is determined. In positive congestion, the arrow is upward. In negative congestion, the arrow is downward.

\subsection{Determining investment strategy}

Type of congestion is determined based on the position of the hyperplane that leans to feasible space. The constraint can identify this position with an equal sign on each division. The overall and divisional efficiency is determined by identifying the free link sign. This sign defines the position of the hyperplane. The slope of the hyperplane specifies the type of congestion. Specifically, after running the model, the type of congestion is determined.

In the definition of strategy, we do not direct an investor only based on the overall and divisional efficiencies. We also consider congestion. The purpose of focusing on congestion in investment is to reach similar congestion with the same direction throughout the supply chain. If the chain has congestions with different signs, investing in congestion with positive sign increases negative congestion in other divisions. If each division of supply chain looks for its profit, its investment on its own strengthens negative congestion in other divisions. This issue negatively affects the sustainability of the whole chain. Therefore, in the proposed strategy, this issue should be prevented. To determine the investment strategy, the following steps are suggested:

Step 1. Select the most sustainable supply chains given maximum overall UE: In this step, sustainable supply chains with maximum overall UE are selected. Given Table 2, supply chains 19 and 34 have maximum efficiency scores.

Step 2. Select supply chains with positive congestion in all divisions: In this step, supply chains with positive congestion in all divisions are selected. In Table 4, congestion of two selected sustainable supply chains in step 1 is analyzed. Supply chain 34 has positive congestion in all divisions. Supply chain 19 has negative congestion in division 4. Therefore, supply chain 34 is selected as an appropriate supply chain for investment.

Step 3. Select inefficient divisions given the average of divisional UE scores: As is shown in Figure 3, division 3 has a minimum average divisional efficiency score compared with other divisions. Therefore, division 3 is selected for investment.

Step 4. After selecting DMU 34 and division 3 for investment, the amount of investment should be determined. Given model $((3.32))$, the amount of investment can be proposed. Congestion is determined by model $((3.32))$. If congestion is positive, the decision maker can increase the amount of investment. Investment is increased as far as congestion is not changed.

Figure 4 depicts the amount of investment in division 3 given congestion. We can see the effect of increasing investment on congestion. As is seen, investing more than 250 billion Rials causes negative congestion in division 3.

Figure 5 depicts the range of investment and its impact on congestion of divisions 3 and 4 . Region $\mathrm{A}$ is a positive congestion region in division 3. Amount of investment in this region ranges from 275667 billion to 300000 billion Rials. Region B is a negative congestion region in division 3. In this region, the amount of investment is over 300000 billion Rials. As is seen, investing more than 300000 billion Rials leads to negative congestion. The amount of investment should be such that type of congestion does not change in any division. Accordingly, region A is an appropriate investment area in division 3. 
TABlE 3. Congestion type in divisions of supply chains.

\begin{tabular}{|c|c|c|c|c|c|c|c|c|c|}
\hline & & \multicolumn{8}{|c|}{ Coefficie $n$ ts indic a ting congestion } \\
\hline & & \multirow{2}{*}{\multicolumn{2}{|c|}{$\begin{array}{c}\text { Papermills and } \\
\text { paperimport } \\
\text { companies }\end{array}$}} & \multirow{2}{*}{\multicolumn{2}{|c|}{$\begin{array}{c}\text { Waste paper } \\
\text { producer }\end{array}$}} & \multicolumn{2}{|c|}{$\begin{array}{l}\text { Waste paper } \\
\text { collecting } \\
\text { companies }\end{array}$} & \multicolumn{2}{|c|}{$\begin{array}{c}\text { Paper recycling } \\
\text { companies }\end{array}$} \\
\hline & & & & & & & $\sigma_{D}$ & & $\sigma_{C}$ \\
\hline DMU 1 & Government Printing Centers & 雨 & 1.284 & 雨 & 0.195 & 雨 & 0.285 & Tत & 0.302 \\
\hline DMU 2 & Government Publishing Center & 雨 & 10.589 & 雨 & 0.797 & 赩 & 0.305 & $\widehat{T}$ & 0.361 \\
\hline DMU 3 & Printing factories of Qom province & $\sqrt{b}$ & -1.099 & 恳 & 0.250 & 斥 & 0.031 & 雨 & 0.291 \\
\hline DMU 4 & Printing factories in Tehran province & 雨 & 0.641 & 布 & 0.122 & 令 & 0.671 & $\sqrt{4}$ & -0.617 \\
\hline DMU 5 & Printers and offices of Tehran Province & 雨 & 5.652 & 雨 & 0.139 & 墒 & 0.400 & T & 0.083 \\
\hline DMU 6 & Printers in Hamedan province & 雨 & 1.220 & 雨 & 0.278 & 郝 & 0.285 & 个 & 0.337 \\
\hline DMU 7 & Printers in Kurdistan Province & 雨 & 0.027 & 雨 & 1.916 & 雨 & 0.400 & 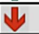 & -0.007 \\
\hline DMU 8 & Amol city printing houses & 雨 & 1.823 & 雨 & 0.047 & 雨 & 0.285 & 不 & 0.204 \\
\hline DMU 9 & Printers of Rasht city & 雨 & 0.834 & 象 & 0.332 & $\sqrt{4}$ & -0.050 & $\sqrt{4}$ & -0.354 \\
\hline DMU 10 & Printers in Lorestan Province & $\sqrt{b}$ & -0.518 & 雨 & 0.430 & 不 & 0.370 & 农 & 0.280 \\
\hline DMU 11 & Tehran Office (District 6 Municipality) & $\sqrt{4}$ & -4.018 & 原 & 0.348 & 原 & 0.285 & 象 & 0.265 \\
\hline DMU 12 & Tehran Office (District 3 Municipality) & 咘 & 0.626 & 雨 & 0.278 & 雨 & 0.504 & 农 & 0.303 \\
\hline DMU 13 & Kerman Municipality & 雨 & 1.488 & 郝 & 0.502 & 雨 & 0.176 & $\sqrt{4}$ & -0.648 \\
\hline DMU 14 & Tehran Office (District 7 Municipality) & 雨 & 13.657 & 雨 & 0.167 & 令 & 0.285 & 雨 & 105.020 \\
\hline DMU 15 & Tehran Office (District 5 Municipality) & 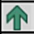 & 0.641 & 雨 & 0.332 & 育 & 0.408 & 象 & 0.171 \\
\hline DMU 16 & Tehran Office (District 2 Municipality) & 斥 & 0.490 & 斥 & 0.014 & 象 & 0.247 & 斥 & 0.303 \\
\hline DMU 17 & Karaj Office (District 2 Municipality) & 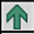 & 0.173 & 雨 & 0.047 & 雨 & 0.473 & $\sqrt{4}$ & -0.567 \\
\hline DMU 18 & Karaj Office (District 3 Municipality) & 个 & 0.626 & 雨 & 0.294 & 雨 & 0.792 & $\sqrt{4}$ & -0.007 \\
\hline DMU 19 & Collection of waste paper in Sanandaj & 办 & 5.470 & 雨 & 0.339 & 厎 & 10.105 & $\sqrt{b}$ & -0.428 \\
\hline DMU 20 & Social Security departments of Tehran and Karaj 1 & 雨 & 0.371 & 雨 & 0.861 & 不 & 0.285 & $\sqrt{ }$ & -1.642 \\
\hline DMU 21 & Social Security departments of Tehran and Karaj 2 & 雨 & 5.038 & 雨 & 0.167 & 象 & 0.317 & 布 & 0.181 \\
\hline DMU 22 & Financial offices of Tehran and Karaj and cities & 个 & 0.626 & 雨 & 0.268 & 刺 & 0.504 & 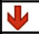 & -0.170 \\
\hline DMU 23 & Social Security departments of Kerman & $\sqrt{4}$ & -1.132 & 雨 & 0.280 & 育 & 0.285 & 雨 & 0.293 \\
\hline DMU 24 & Social Security departments of Qom & 雨 & 1.316 & 令 & 0.165 & 雨 & 0.180 & $\downarrow$ & -0.727 \\
\hline DMU 25 & Center for the expropriation of government documents & 布 & 0.626 & 雨 & 0.332 & 赩 & 0.305 & 雨 & 0.303 \\
\hline DMU 26 & Collection of waste paper in Tehran 1 & 斥 & 0.486 & 雨 & 0.391 & 象 & 0.278 & 农 & 3.912 \\
\hline DMU 27 & Collection of waste paper in Tehran 2 & $\sqrt{4}$ & -0.518 & 原 & 0.250 & 墒 & 0.180 & $\hat{\imath}$ & 1.992 \\
\hline DMU 28 & Collection of waste paper in Tehran 3 & 雨 & 2.074 & 邻 & 0.227 & 邻 & 0.511 & 舟 & 0.347 \\
\hline DMU 29 & Collection of waste paper in Shahriar1 & 雨 & 5.795 & 恳 & 0.047 & 恳 & 0.305 & 农 & 0.343 \\
\hline DMU 30 & Collection of waste paper in Azerbaijan & 斥 & 0.406 & 斥 & 0.307 & 斥 & 0.370 & 斥 & 0.315 \\
\hline DMU 31 & Collection of waste paper in Northern cities of Iran & 斥 & 0.945 & 原 & 0.634 & 奥 & 0.285 & 斥 & 0.396 \\
\hline DMU 32 & Collection of waste paper in Hashtgerd & $\sqrt{b}$ & -0.115 & 雨 & 1.251 & 不 & 0.455 & 个 & 0.303 \\
\hline DMU 33 & Collection of waste paper in Kerman & 斥 & 0.295 & 雨 & 0.348 & 急 & 0.285 & $凶$ & -0.437 \\
\hline DMU 34 & Social Security departments of Tehran and Karaj 3 & 斥 & 1.045 & 个 & 0.165 & 个 & 0.313 & 雨 & 6.624 \\
\hline DMU 35 & Social Security departments of Tehran and Karaj 4 & $\sqrt{4}$ & -0.757 & 雨 & 0.433 & 象 & 0.285 & $\sqrt{4}$ & -1.526 \\
\hline DMU 36 & Collection of waste paper in Qorveh & 布 & 0.396 & 雨 & 0.268 & 象 & 1.391 & $\sqrt{ }$ & -1.445 \\
\hline DMU 37 & Hamedan City Banks & 雨 & 0.641 & 斥 & 0.398 & 压 & 0.305 & $\sqrt{b}$ & -4.096 \\
\hline DMU 38 & Collection of waste paper in Shahriar2 & 雨 & 0.626 & 压 & 0.294 & 奥 & 1.197 & 雨 & 0.343 \\
\hline DMU 39 & Collection of waste paper in Marivan & 而 & 4.535 & $\sqrt{4}$ & -1.535 & 原 & 0.285 & 雨 & 0.278 \\
\hline DMU 40 & Social Security departments of Tehran and Karaj 5 & $\sqrt{\omega}$ & -0.510 & 雨 & 0.014 & 奕 & 0.434 & 皮 & 0.181 \\
\hline DMU 41 & $\begin{array}{l}\text {.Aria Cellulose Trading Co } \\
\end{array}$ & 斥 & 0.626 & 舟 & 0.121 & 奥 & 0.305 & 雨 & 0.395 \\
\hline DMU 42 & Razavi Cellulose Trading Co & 个 & 0.626 & 雨 & 0.296 & 象 & 0.313 & $\downarrow$ & -3.878 \\
\hline DMU 43 & Iranian Justice Offices & 斥 & 0.626 & 斥 & 0.268 & 雨 & 0.305 & 雨 & 0.204 \\
\hline DMU 44 & Waste Paper Bank of SADERAT & 斥 & 0.499 & 斥 & 0.861 & 斥 & 0.285 & 布 & 0.278 \\
\hline DMU 45 & Waste Paper National Bank & 皮 & 0.558 & $\sqrt{4}$ & -0.066 & 雨 & 12.486 & 皮 & 1.668 \\
\hline DMU 46 & Waste Paper Bank Refah Kargaran & 雨 & 1.341 & $\sqrt{4}$ & -0.041 & $\widehat{T}$ & 0.285 & $\downarrow$ & -0.575 \\
\hline DMU 47 & Margin cut printing Hamshahri news papar & 斥 & 0.289 & 雨 & 2.510 & 个 & 0.370 & $\sqrt{v}$ & -0.707 \\
\hline DMU 48 & Margin cut printing Keyhan news papar & 个 & 0.996 & 雨 & 5.704 & 象 & 0.876 & 斥 & 0.303 \\
\hline DMU 49 & Margin cut printing Astan Qods Razavi & $\sqrt{b}$ & -5.540 & 雨 & 0.278 & 象 & 0.285 & $\sqrt{b}$ & -0.654 \\
\hline DMU 50 & Iran Textbooks Print & 雨 & 0.626 & $凶$ & -0.090 & 斥 & 0.278 & 雨 & 0.347 \\
\hline
\end{tabular}


TABLE 4. Comparison of two supply chains.

\begin{tabular}{|c|c|c|c|c|c|}
\hline & & \multicolumn{4}{|c|}{ Coefficients indicating congestion } \\
\hline & & $\begin{array}{l}\text { Paper mills and } \\
\text { paper import } \\
\text { companies }\end{array}$ & $\begin{array}{l}\text { Waste paper } \\
\text { producer }\end{array}$ & $\begin{array}{l}\text { Waste paper } \\
\text { collecting } \\
\text { companies }\end{array}$ & $\begin{array}{l}\text { Paper } \\
\text { recycling } \\
\text { companies }\end{array}$ \\
\hline & & $\sigma_{s}$ & $\sigma_{M}$ & $\sigma_{D}$ & $\sigma_{C}$ \\
\hline DMU 19 & Collection of waste paper in Sanandaj & 5.470 & 0.339 & 10.105 & -0.428 \\
\hline DMU 34 & Social Security departments of Tehran and Karaj 3 & 1.045 & 0.165 & 0.313 & 6.624 \\
\hline
\end{tabular}

\begin{tabular}{|c|c|c|c|c|}
\hline $\begin{array}{c}\text { Amount of } \\
\text { investment }\end{array}$ & $\begin{array}{c}\text { Paper } \\
\text { mills and } \\
\text { paper } \\
\text { import } \\
\text { companies }\end{array}$ & $\begin{array}{c}\text { Waste } \\
\text { paper } \\
\text { producer }\end{array}$ & $\begin{array}{c}\text { Waste } \\
\text { paper } \\
\text { collecting } \\
\text { companies }\end{array}$ & $\begin{array}{c}\text { Paper } \\
\text { recycling } \\
\text { companies }\end{array}$ \\
\hline Billion Rials & $\sigma_{s}$ & $\sigma_{M}$ & $\sigma_{D}$ & $\sigma_{C}$ \\
\hline 81 & 1.045 & 0.165 & 0.313 & 6.624 \\
\hline 100 & 1.048 & 0.166 & 0.281 & 6.345 \\
\hline 119 & 1.051 & 0.166 & 0.263 & 6.066 \\
\hline 138 & 1.055 & 0.166 & 0.214 & 5.788 \\
\hline 157 & 1.058 & 0.167 & 0.165 & 5.509 \\
\hline 176 & 1.062 & 0.167 & 0.163 & 5.230 \\
\hline 195 & 1.065 & 0.168 & 0.125 & 4.952 \\
\hline 214 & 1.069 & 0.168 & 0.113 & 4.673 \\
\hline 233 & 1.072 & 0.168 & 0.071 & 4.394 \\
\hline 252 & 1.076 & 0.169 & 0.032 & 4.116 \\
\hline 270 & 1.079 & 0.169 & 0.012 & 3.837 \\
\hline 290 & 1.083 & -0.010 & -0.012 & 1.526 \\
\hline 300 & 1.086 & -0.080 & -0.043 & -0.034 \\
\hline
\end{tabular}

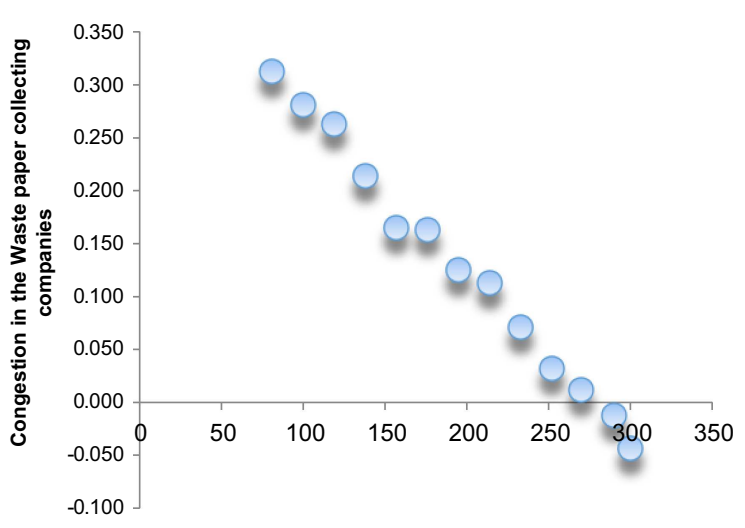

Amount of investment in billion Rials

FigURE 4. Impact of investment changes on congestion type.

Figure 6 shows the impact of investment on the congestion of DMU 34 in 4 divisions. As is shown, by the increasing amount of investment, congestion is determined. If congestion is positive, then the decision maker can increase investment. However, the direction of congestion should not be negative. Investment from 275 billion to 300 billion Rials does not lead to negative congestion of the division being invested.

As mentioned before, in step 1, supply chains with maximum overall UE are selected (supply chains 19 and 34). In step 2, the supply chain with positive congestion in all divisions is selected (supply chain 34). In step 3, the inefficient division given the average of divisional UE score is selected (division 3). Finally, in step 4, after selecting DMU 34 and division 3 for investment, amount of investment and congestion type given model ((3.32)) should be determined. Given the results, the best choice is to establish a waste paper collecting company with a capital of $275-300$ billion Rials while congestion type is not changed.

In the efficiency evaluation, paying attention to economic factors is simple for analysts. However, without an integrated approach, it is complicated to take into account social and environmental factors. An integrated approach assists supply chain analysts to get a full view of sustainability. The proposed model deals with environmental, social, and economic factors, simultaneously.

\section{MANAGERIAL impliCATIONS}

Nowadays, due to government regulations and increasing public awareness about sustainability, companies attempt to improve their sustainability. A company can survive if it is capable of creating and retaining a sustainable relationship with all of its stakeholders $[48,50]$. Furthermore, corporate decision makers comprehend that sustainability can create a competitive advantage for them [42]. A company that takes into account environmental, economic, and social factors in its processes is called a sustainable company [10,41,48]. Currently, competition is among supply chains $[39,59]$. Companies should invest in the sustainability of supply chains 


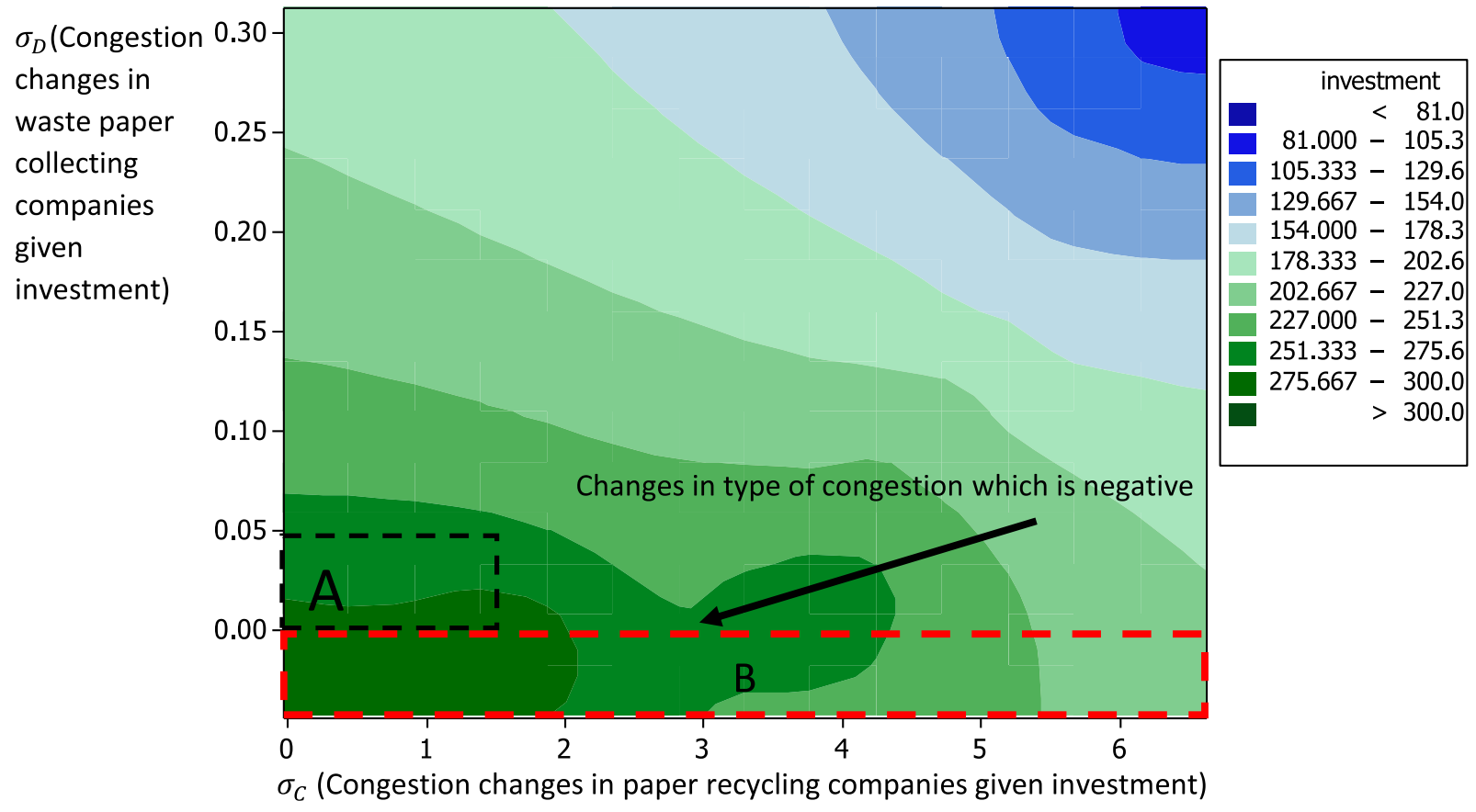

FiguRE 5. Investment ranges and its impact on congestion of divisions 3 and 4.

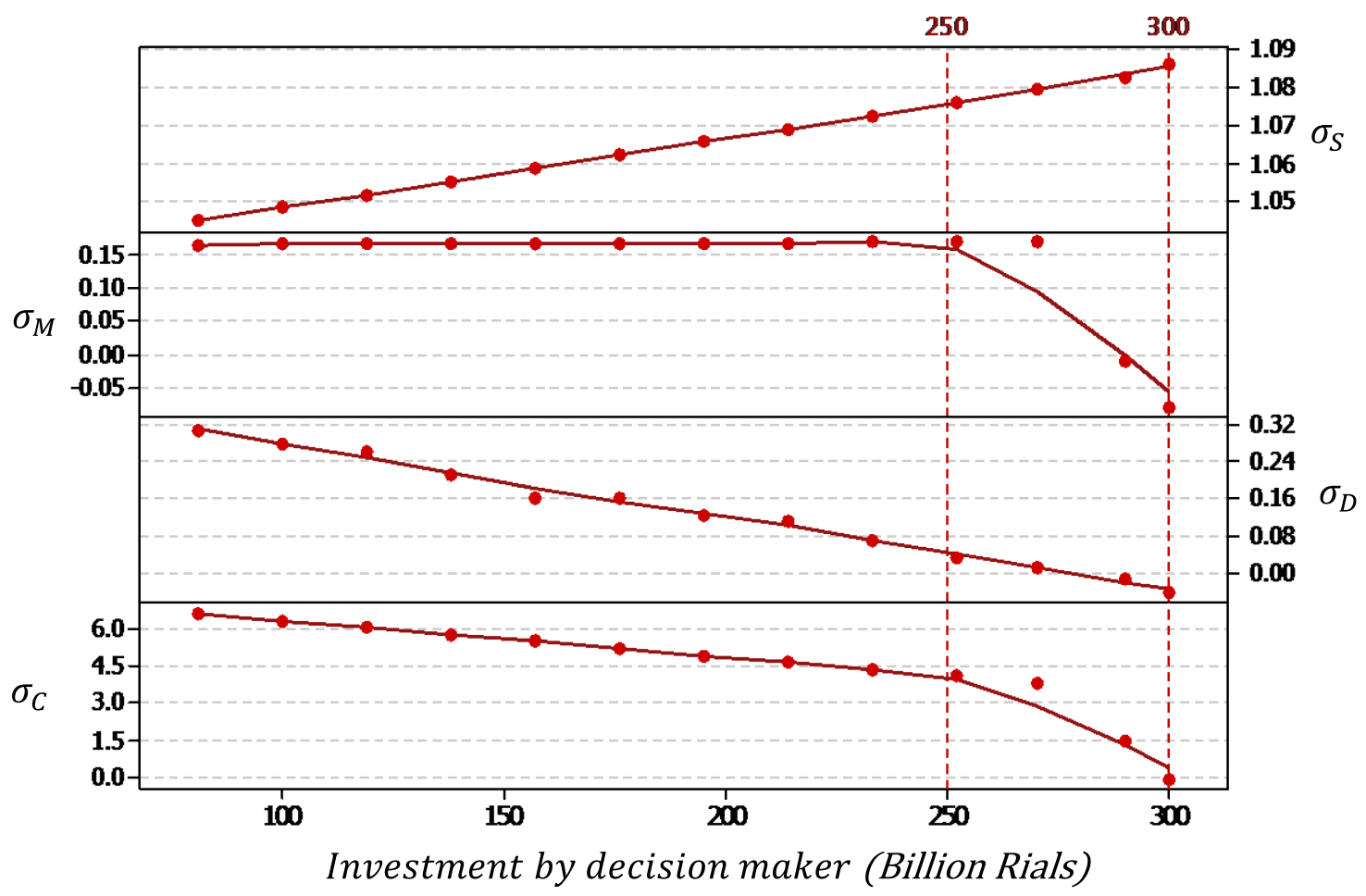

FIGURE 6. Impact of investment on congestion in 4 divisions of DMU 34. 
$[6,30,59]$. In this paper, we proposed an adaptive RAM network model to assess the sustainability of supply chains. We identified opportunities for investment in supply chains. Our proposed model introduced investment opportunities given managerial disposability, natural disposability, and undesirable outputs. We determined the type of congestion. In other words, our adaptive network DEA model can determine the amount of investment concerning sustainability factors and type of congestion.

\section{Conclusions}

Globalization has forced managers to change their traditional approaches to supply chain level and consider interactions among different parts of supply chains [8]. Also, by increasing globalization of supply chains, decision-makers have focused on the sustainability of supply chains [8]. Sustainable SCM is a growing topic [56]. A decision maker should consider an appropriate amount of investment in sustainability aspects. In this paper, we proposed an adaptive network DEA model to assess the sustainability of supply chains. For the first time, we proposed an adaptive RAM network model. Our model can evaluate the relative efficiency of DMUs and determine the amount of investment in sustainable supply chains. Moreover, our proposed model introduced investment opportunities given the type of congestion.

We suggest the following topics for future researchers:

- Developing a network dynamic RAM model to take into account managerial and natural disposability.

- Developing an inverse network dynamic RAM model.

\section{APPENDIX}

See Tables A.1, A.2, A.3 and A.4 in below. 


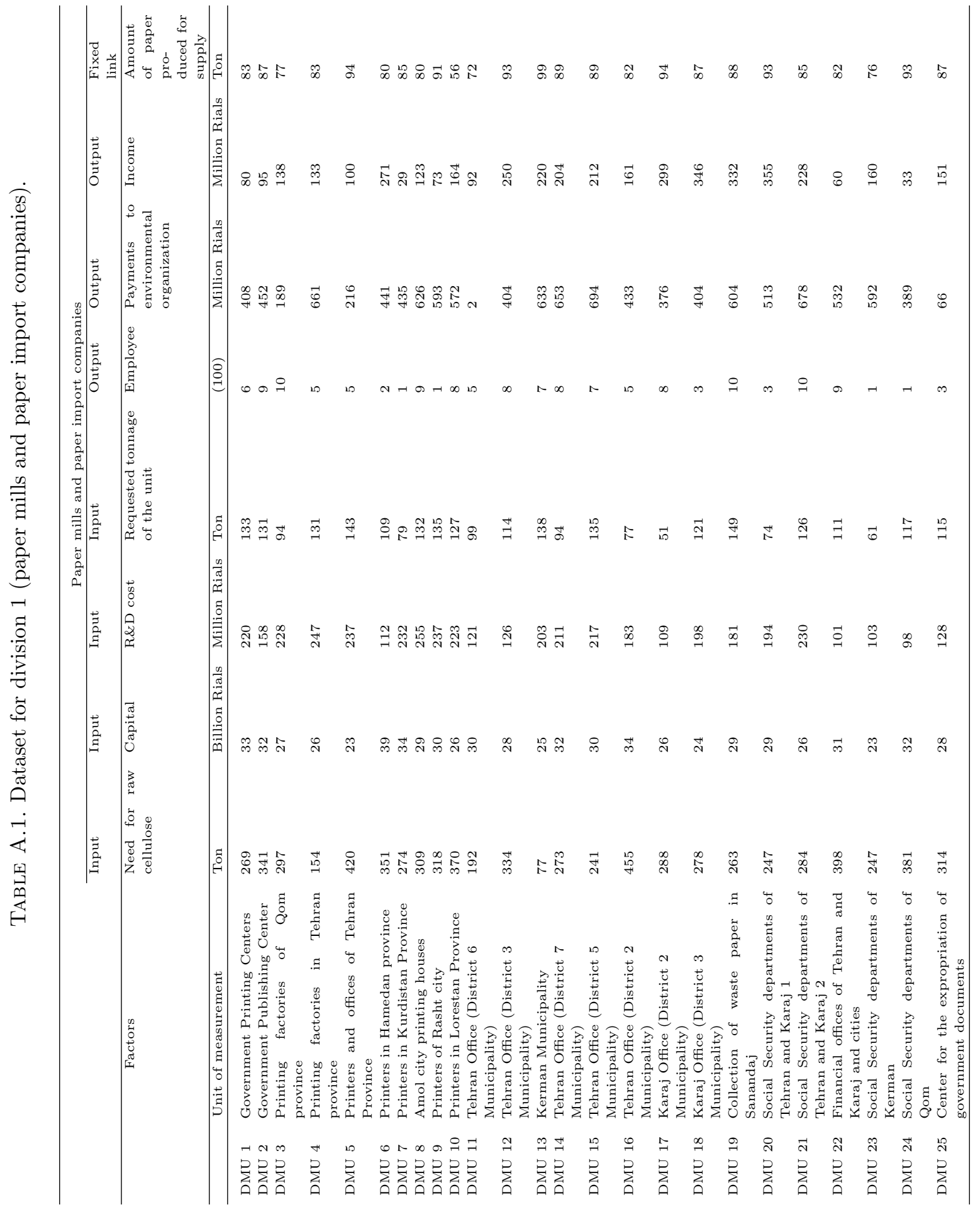




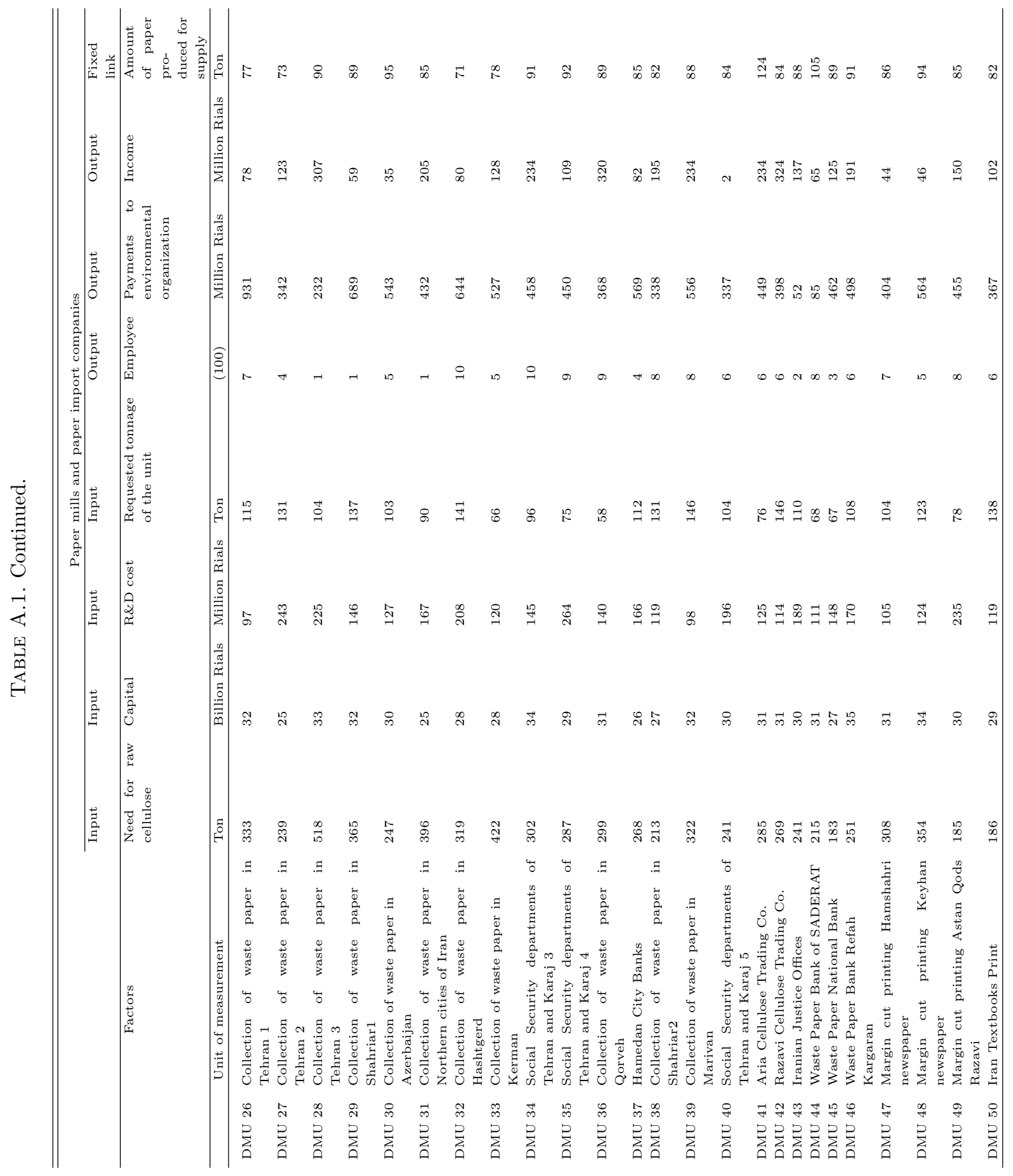




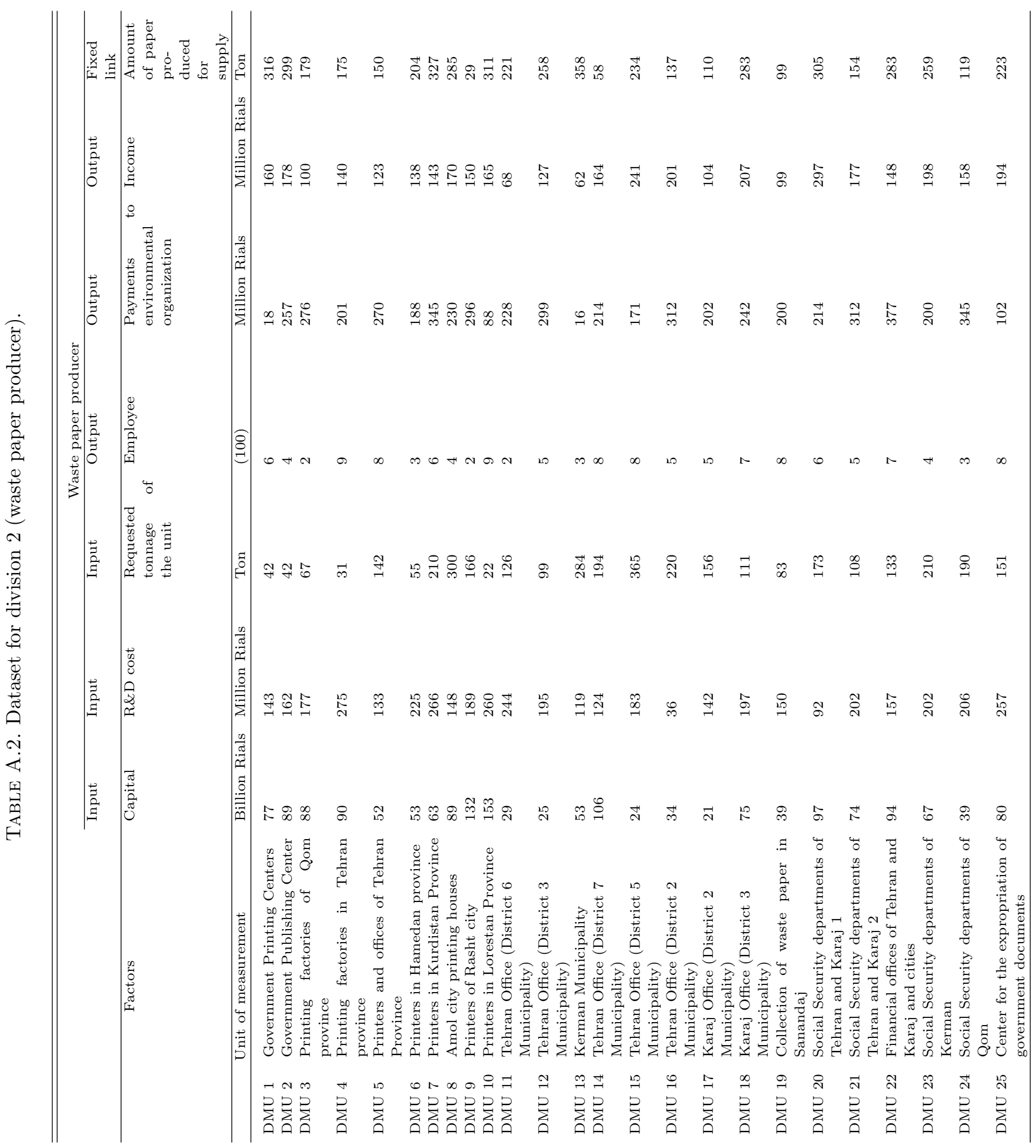




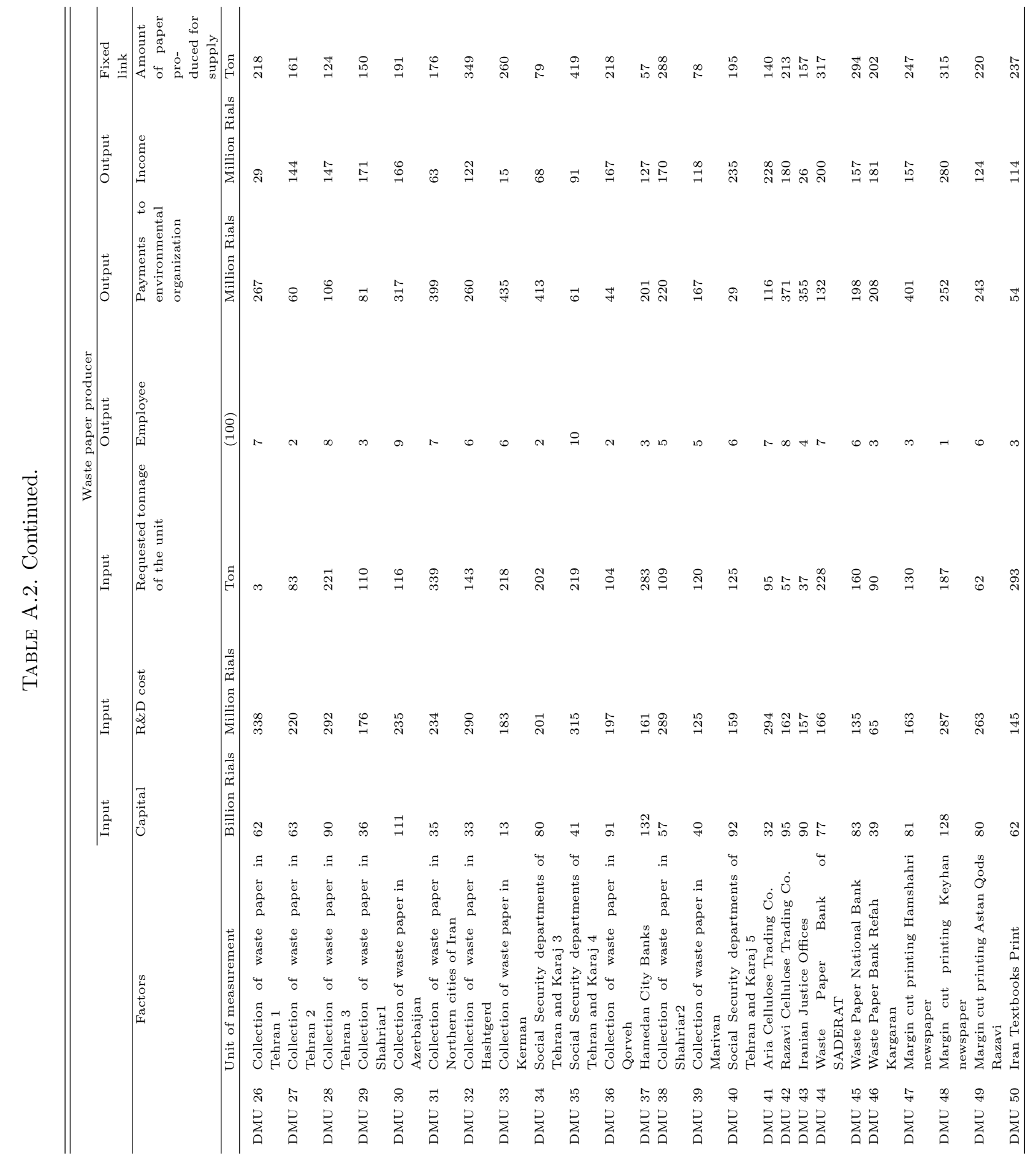




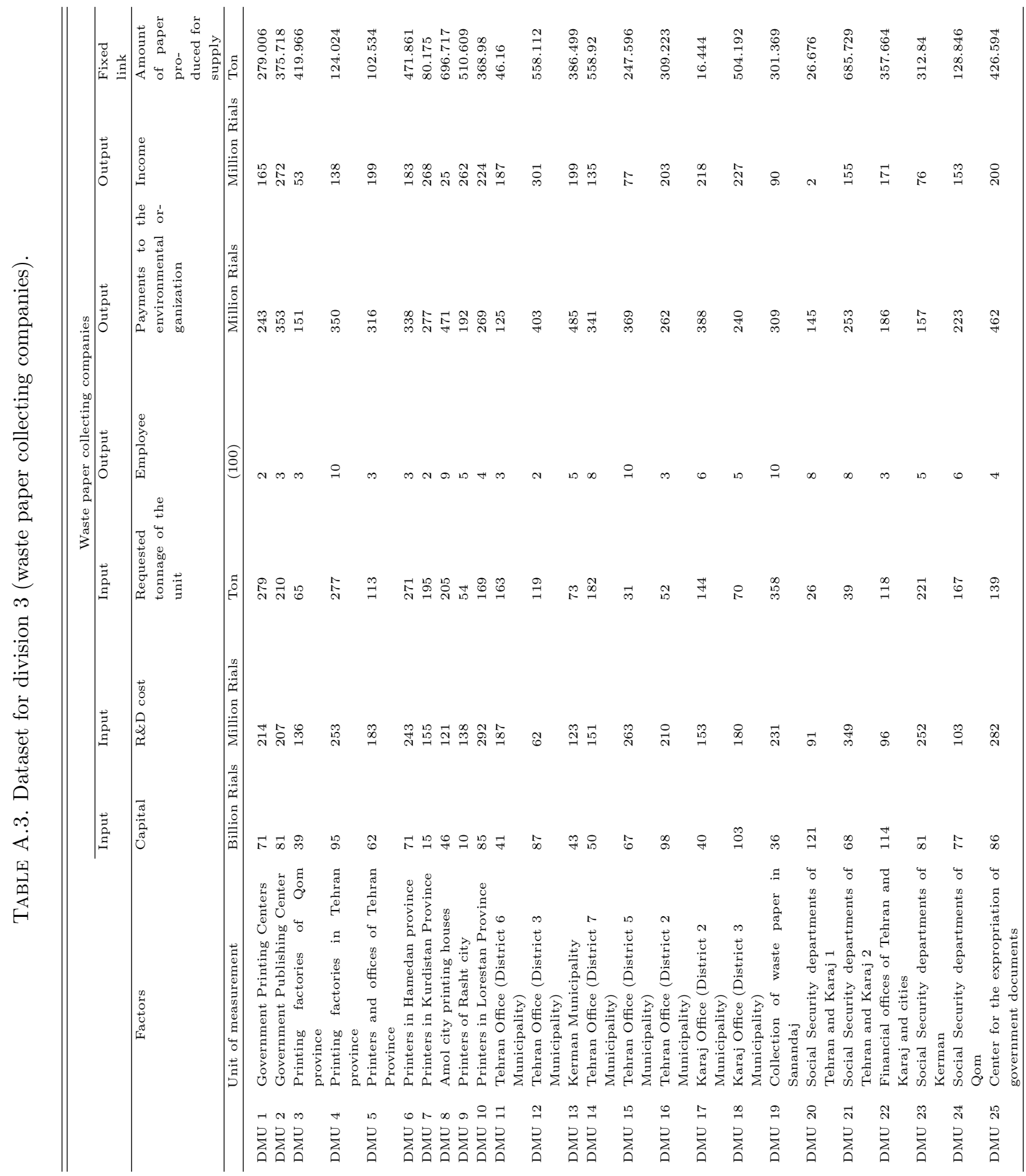




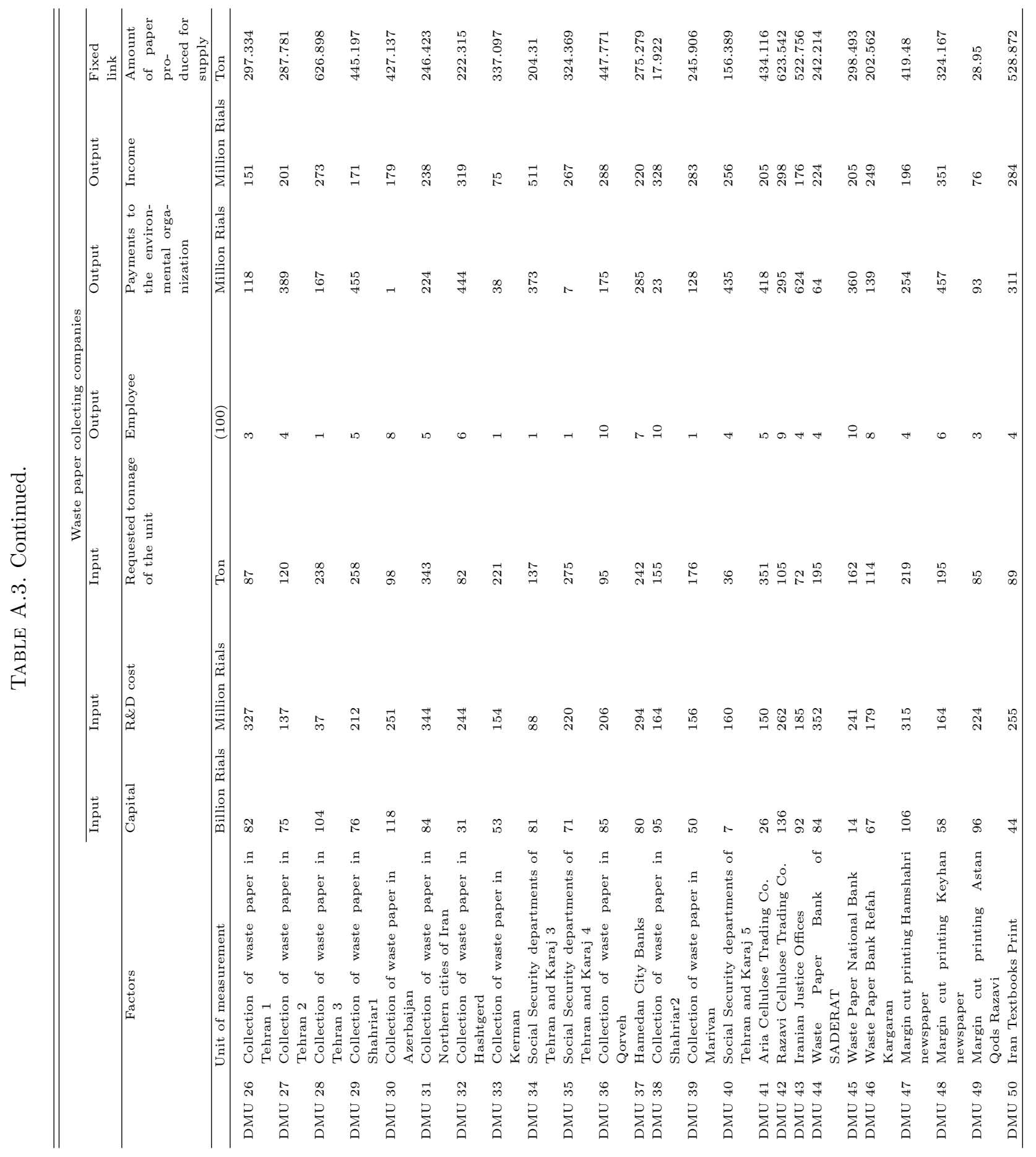




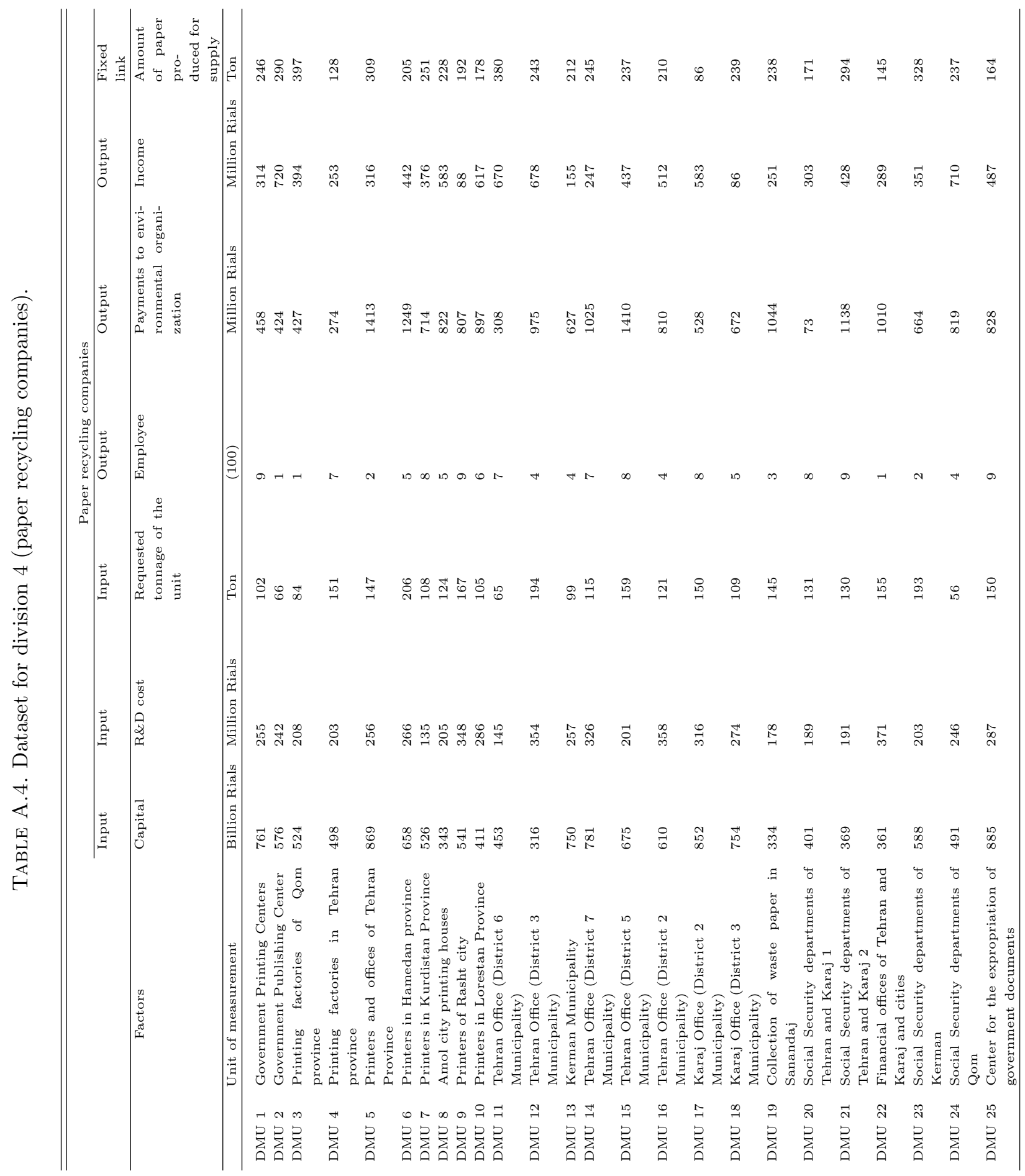




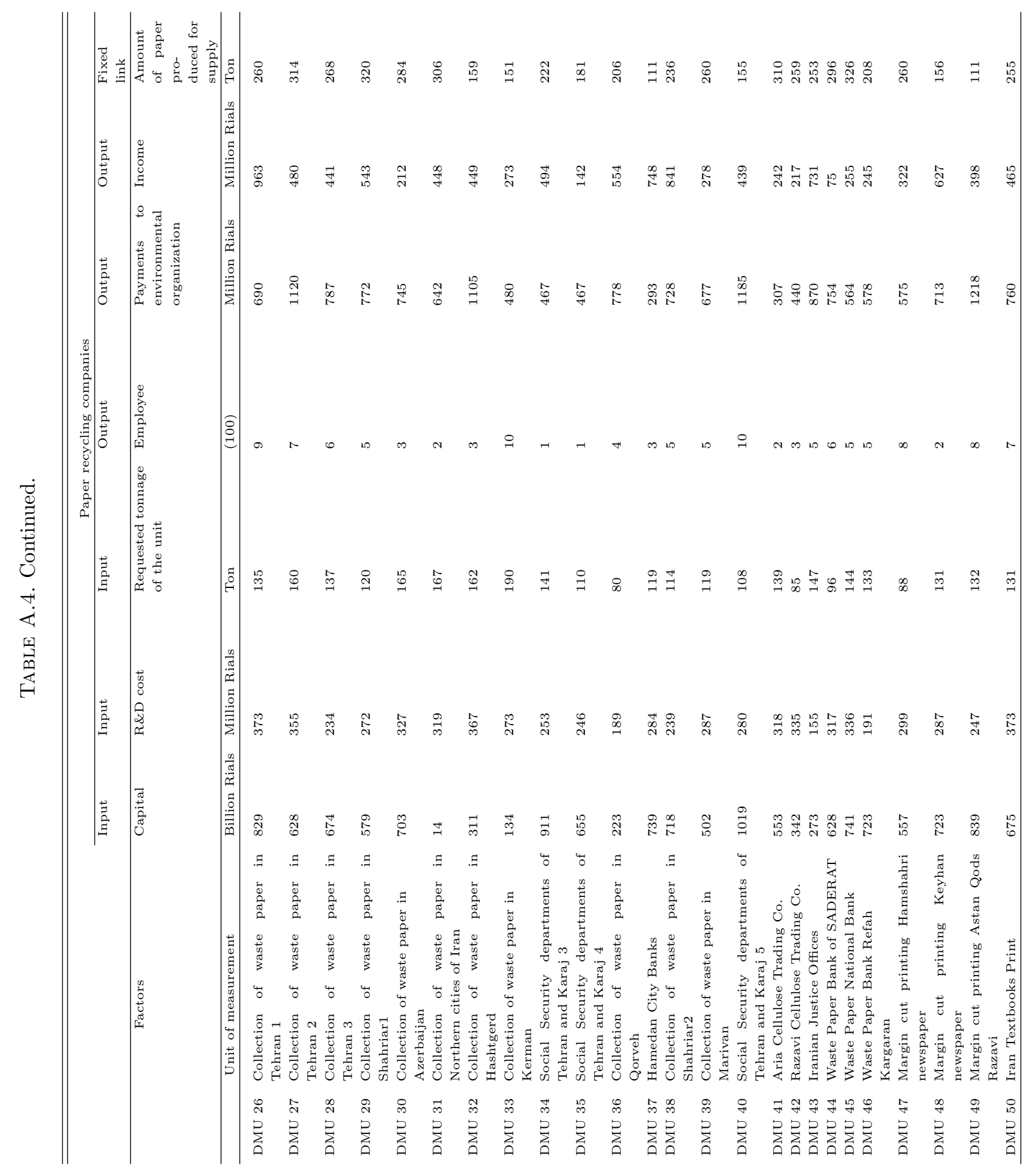




\section{REFERENCES}

[1] P.J. Agrell and A. Hatami-Marbini, Frontier-based performance analysis models for supply chain management: State of the art and research directions. Comput. Ind. Eng. 66 (2013) 567-583.

[2] N.K. Avkiran and A. McCrystal, Sensitivity analysis of network DEA: NSBM versus NRAM. Appl. Math. Comput. 218 (2012) 11226-11239.

[3] M. Azadi, M. Jafarian, R. Farzipoor Saen and S.M. Mirhedayatian, A new fuzzy DEA model for evaluation of efficiency and effectiveness of suppliers in sustainable supply chain management context. Comput. Oper. Res. 54 (2015) $274-285$.

[4] T. Badiezadeh, R. Farzipoor Saen and T. Samavati, Assessing sustainability of supply chains by double frontier network DEA: A big data approach. Comput. Oper. Res. 98 (2018) 284-290.

[5] R.D. Banker, A. Charnes and W.W. Cooper, Some models for estimating technical and scale inefficiencies in data envelopment analysis. Manag. Sci. 30 (1984) 1078-1092.

[6] A.P. Barbosa-Póvoa, Sustainable supply chains: Key challenges. Comput. Aided Chem. Eng. 27 (2009) $127-132$.

[7] E. Boudaghi and R.F. Saen, Developing a novel model of data envelopment analysis-discriminant analysis for predicting group membership of suppliers in sustainable supply chain. Comput. Oper. Res. 89 (2018) 348-359.

[8] R. Burritt and S. Schaltegger, Accounting towards sustainability in production and supply chains. Br. Acc. Rev. 46 (2014) $327-343$.

[9] D. Carlsson, S. D'Amours, A. Martel and M. Rönnqvist, Supply chain planning models in the pulp and paper industry. INFOR: Inf. Syst. Oper. Res. 47 (2009) 167-183.

[10] C.R. Carter and D.S. Rogers, A framework of sustainable supply chain management: Moving toward new theory. Int. J. Phys. Distrib. Logist. Manag. 38 (2008) 360-387.

[11] A. Charnes, W. Cooper, B. Golany, R. Halek, G. Klopp, E. Schmitz and D. Thomas, Two Phase Data Envelopment Analysis Approaches to Policy Evaluation and Management of Army Recruiting Activities: Tradeoffs Between Joint Services and Army Advertising: Center for Cybernetic Studies. University of Texas-Austin, Austin, Texas, USA (1986).

[12] A. Charnes, W.W. Cooper and E. Rhodes, Measuring the efficiency of decision making units. Eur. J. Oper. Res. 2 (1978) 429-444.

[13] C.M. Chen, A network-DEA model with new efficiency measures to incorporate the dynamic effect in production networks. Eur. J. Oper. Res. 194 (2009) 687-699.

[14] Y. Chen, W.D. Cook, N. Li and J. Zhu, Additive efficiency decomposition in two-stage DEA. Eur. J. Oper. Res. 196 (2009) 1170-1176.

[15] Y. Chen, W.D. Cook, C. Kao and J. Zhu, Network DEA pitfalls: Divisional efficiency and frontier projection. In: Data Envelopment Analysis. Springer, Boston, MA (2014) 31-54.

[16] K. Chen and J. Zhu, Second order cone programming approach to two-stage network data envelopment analysis. Eur. J. Oper. Res. 262 (2017) 231-238.

[17] C. Chen, J. Zhu, J.Y. Yu and H. Noori, A new methodology for evaluating sustainable product design performance with two-stage network data envelopment analysis. Eur. J. Oper. Res. 221 (2012) 348-359.

[18] W.D. Cook, K. Tone and J. Zhu, Data envelopment analysis: Prior to choosing a model. Omega 44 (2014) 1-4.

[19] W.W. Cooper, H. Deng, B. Gu, S. Li and R.M. Thrall, Using DEA to improve the management of congestion in Chinese industries (1981-1997), Socio-Econ. Plan. Sci. 35 (2001) 227-242.

[20] W.W. Cooper, K.S. Park and J.T. Pastor, RAM: A range adjusted measure of inefficiency for use with additive models, and relations to other models and measures in DEA. J. Prod. Anal. 11 (1999) 5-42.

[21] W.W. Cooper, L.M. Seiford, K. Tone, Data Envelopment Analysis: A Comprehensive Text with Models, Application, References and DEA-Solver Software. Kluwer Academic publishers (2002).

[22] D.K. Despotis, G. Koronakos and D. Sotiros, Composition versus decomposition in two-stage network DEA: A reverse approach. J. Prod. Anal. 45 (2016) 71-87.

[23] T. Dyllick and K. Hockerts, Beyond the business case for corporate sustainability. Bus. Strat. Environ. 11 (2002) $130-141$.

[24] R. Färe and S. Grosskopf, Network DEA. Socio-Econ. Plan. Sci. 34 (2000) 35-49.

[25] R. Färe and S. Grosskopf, Modeling undesirable factors in efficiency evaluation: Comment. Eur. J. Oper. Res. 157 (2004) $242-245$.

[26] R. Farzipoor Saen, A decision model for selecting technology suppliers in the presence of nondiscretionary factors. Appl. Math. Comput. 181 (2006) 1609-1615.

[27] R. Farzipoor Saen, Developing a new data envelopment analysis methodology for supplier selection in the presence of both undesirable outputs and imprecise data. Int. J. Adv. Manuf. Technol. 51 (2010) 1243-1250.

[28] A. Fathi and R. Farzipoor Saen, A novel bidirectional network data envelopment analysis model for evaluating sustainability of distributive supply chains of transport companies. J. Clean. Prod. 184 (2018) 696-708.

[29] G. Gosalbez, A. Martin and L. Stamford, Enhanced data envelopment analysis for sustainability assessment: A novel methodology and application to electricity technologies. Comput. Chem. Eng. 90 (2016) 188-200.

[30] I.E. Grossmann, Challenges in the new millennium: Product discovery and design, enterprise and supply chain optimization, global life cycle assessment. Comput. Chem. Eng. 29 (2004) 29-39.

[31] A. Hassanzadeh, S. Yousefi, R. Farzipoor Saen and S.S.S. Hosseininia, How to assess sustainability of countries via inverse data envelopment analysis? Clean Technol. Environ. Policy 20 (2018) 29-40. 
[32] C.W. Hsu and A.H. Hu, Green supply chain management in the electronic industry. Int. J. Environ. Sci. Technol. 5 (2008) $205-216$.

[33] M. Izadikhah and R. Farzipoor Saen, Evaluating sustainability of supply chains by two-stage range directional measure in the presence of negative data, Transp. Res. Part D: Transp. Environ. 49 (2016) 110-126.

[34] M. Izadikhah and R. Farzipoor Saen, Assessing sustainability of supply chains by chance-constrained two-stage DEA model in the presence of undesirable factors. Comput. Oper. Res. 100 (2018) 343-367.

[35] J. Jassbi, R. Farzipoor Saen, F. Hosseinzadeh Lotfi and S.S. Hosseininia, A hybrid decision making system using DEA and fuzzy models for supplier selection in the presence of multiple decision makers. Int. J. Ind. Math. 3 (2011) 193-212.

[36] S. Jradi, T.B. Chameeva, B. Delhomme and A. Jaegler, Tracking carbon footprint in French vineyards: A DEA performance assessment. J. Clean. Prod. 192 (2018) 43-54.

[37] C. Kao, Network data envelopment analysis: A review. Eur. J. Oper. Res. 239 (2014) 1-16.

[38] C. Kao and S.N. Hwang, Efficiency decomposition in two-stage data envelopment analysis: An application to non-life insurance companies in Taiwan. Eur. J. Oper. Res. 185 (2008) 418-429.

[39] D.J. Ketchen and G.T.M. Hult, Bridging organization theory and supply chain management: The case of best value supply chains. J. Oper. Manag. 25 (2007) 573-580.

[40] G. Koronakos, D. Sotiros and D.K. Despotis, Reformulation of network data envelopment analysis models using a common modelling framework. Eur. J. Oper. Res. 278 (2019) 472-480.

[41] G. Lamberton, Sustainability accounting. A brief history and conceptual framework. Acc. Forum 29 (2005) 7-26.

[42] M. Mahdiloo, M. Tavana, R. Farzipoor Saen and A. Noorizadeh, A game theoretic approach to modeling undesirable outputs and efficiency decomposition in data envelopment analysis. Appl. Math. Comput. 244 (2014) 479-492.

[43] Y. Maruyama, Range adjusted measure network DEA model. AIP Conf. Proc. 1168 (2009) 949-952.

[44] S.M. Mirhedayatian, M. Azadi and R. Farzipoor Saen, A novel network data envelopment analysis model for evaluating green supply chain management. Int. J. Prod. Econ. 147 (2014) 544-554.

[45] B. Mota, M.I. Gomes and A.P. Barbosa-Póvoa, Supply chain design towards sustainability: Accounting for growth and jobs. Comput. Aided Chem. Eng. 34 (2014) 789-794.

[46] P.R. Murphy and R.F. Poist, Green perspectives and practices: a "comparative logistics" study. Supply Chain Manag.: Int. J. 8 (2003) 122-131.

[47] J.Q.F. Neto, J.M. Bloemhof-Ruwaard, J.A. van Nunen and E. van Heck, Designing and evaluating sustainable logistics networks. Int. J. Prod. Econ. 111 (2008) 195-208.

[48] F. Perrini and A. Tencati, Sustainability and stakeholder management: The need for new corporate performance evaluation and reporting systems. Bus. Strat. Environ. 15 (2006) 296-308.

[49] A. Philpott and G. Everett, Supply chain optimisation in the paper industry. Ann. Oper. Res. 108 (2001) $225-237$.

[50] J.E. Post, L.E. Preston and S. Sachs, Managing the extended enterprise: The new stakeholder view. Calif. Manag. Rev. 45 (2002) 6-28

[51] A. Qorri, Z. Mujkić and A. Kraslawski, A conceptual framework for measuring sustainability performance of supply chains. J. Clean. Prod. 189 (2018) 570-584.

[52] K. Rashidi and R. Farzipoor Saen, Measuring eco-efficiency based on green indicators and potentials in energy saving and undesirable output abatement. Energy Econ. 50 (2015) 18-26.

[53] H. Scheel, Undesirable outputs in efficiency valuations. Eur. J. Oper. Res. 132 (2001) 400-410.

[54] L.M. Seiford and J. Zhu, Profitability and marketability of the top 55 US commercial banks. Manag. Sci. 45 (1999) $1270-1288$.

[55] L.M. Seiford and J. Zhu, Modeling undesirable factors in efficiency evaluation. Eur. J. Oper. Res. 142 (2002) 16-20.

[56] S. Seuring and M. Müller, Core issues in sustainable supply chain management-a Delphi study. Bus. Strat. Environ. 17 (2008) $455-466$.

[57] V. Shokri Kahi, S. Yousefi, H. Shabanpour and R. Farzipoor Saen, How to evaluate sustainability of supply chains? A dynamic network DEA approach. Ind. Manag. Data Syst. 117 (2017) 1866-1889.

[58] S. Soheilirad, K. Govindan, A. Mardani, E.K. Zavadskas, M. Nilashi and N. Zakuan, Application of data envelopment analysis models in supply chain management: A systematic review and meta-analysis. Ann. Oper. Res. 271 (2018) $915-969$.

[59] L.J. Spence and L. Rinaldi, Governmentality in accounting and accountability: A case study of embedding sustainability in a supply chain. Acc. Organ. Soc. 39 (2014) 433-452.

[60] T. Sueyoshi and M. Goto, Should the US clean air act include CO2 emission control?: Examination by data envelopment analysis. Energy Policy 38 (2010) 5902-5911.

[61] T. Sueyoshi and M. Goto, Methodological comparison between two unified (operational and environmental) efficiency measurements for environmental assessment. Eur. J. Oper. Res. 210 (2011) 684-693.

[62] T. Sueyoshi and M. Goto, Data envelopment analysis for environmental assessment: Comparison between public and private ownership in petroleum industry. Eur. J. Oper. Res. 216 (2012) 668-678.

[63] T. Sueyoshi and M. Goto, Undesirable congestion under natural disposability and desirable congestion under managerial disposability in US electric power industry measured by DEA environmental assessment. Energy Econ. 55 (2016) 173-188.

[64] T. Sueyoshi and D. Wang, Sustainability development for supply chain management in US petroleum industry by DEA environmental assessment. Energy Econ. 46 (2014) 360-374.

[65] A. Tajbakhsh and E. Hassini, A data envelopment analysis approach to evaluate sustainability in supply chain networks. J. Clean. Prod. 105 (2015) 74-85. 
[66] A. Tajbakhsh and E. Hassini, Evaluating sustainability performance in fossil-fuel power plants using a two-stage data envelopment analysis. Energy Econ. 74 (2018) 154-178.

[67] M. Tavana, H. Shabanpour, S. Yousefi and R. Farzipoor Saen, A hybrid goal programming and dynamic data envelopment analysis framework for sustainable supplier evaluation. Neural Comput. Appl. 28 (2017) 3683-3696.

[68] M. Tavassoli and R. Farzipoor Saen, Predicting group membership of sustainable suppliers via data envelopment analysis and discriminant analysis. Sustain. Prod. Consum. 18 (2019) 41-52.

[69] M. Tavassoli, R. Farzipoor Saen and G.R. Faramarzi, Developing network data envelopment analysis model for supply chain performance measurement in the presence of zero data. Expert Syst. 32 (2015) 381-391.

[70] S. Yousefi, R. Farzipoor Saen and S.S. Seyedi Hosseininia, Developing an inverse range directional measure model to deal with positive and negative values. Manag. Decis. 57 (2019) 2520-2540.

[71] H. Zhou, Y. Yang, Y. Chen and J. Zhu, Data envelopment analysis application in sustainability: The origins, development and future directions. Eur. J. Oper. Res. 264 (2018) 1-16.

[72] K.H. Zoroufchi, M. Azadi and R. Farzipoor Saen, Developing a new cross-efficiency model with undesirable outputs for supplier selection. Int. J. Ind. Syst. Eng. 12 (2012) 470-484. 